\title{
Transportation Sector Market Transition: Using History and Geography to Envision Possible Hydrogen Infrastructure Development and Inform Public Policy
}

Elizabeth Brown

Technical Report NREL/TP-670-43497

August 2008

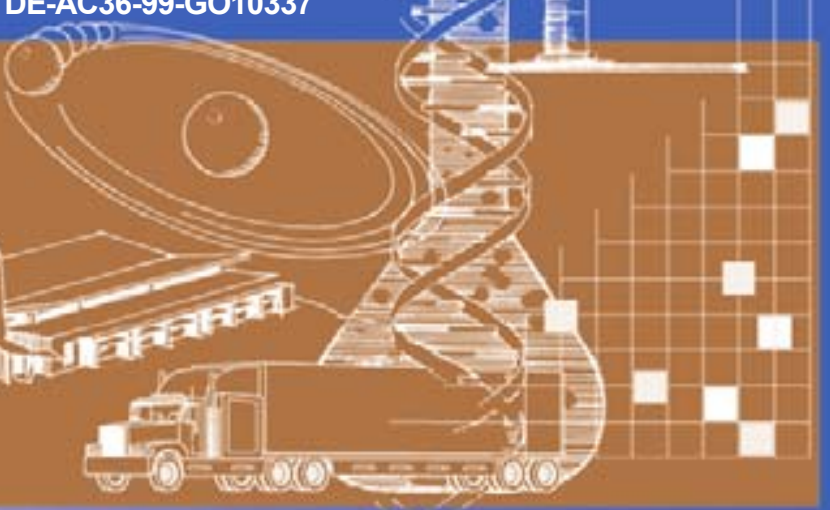




\section{Transportation Sector Market Transition: Using History and Geography to Envision Possible Hydrogen Infrastructure Development and Inform Public Policy}

\section{Elizabeth Brown}

Prepared under Task No. H278.2700

National Renewable Energy Laboratory 1617 Cole Boulevard, Golden, Colorado 80401-3393 303-275-3000 - www.nrel.gov 


\section{NOTICE}

This report was prepared as an account of work sponsored by an agency of the United States government. Neither the United States government nor any agency thereof, nor any of their employees, makes any warranty, express or implied, or assumes any legal liability or responsibility for the accuracy, completeness, or usefulness of any information, apparatus, product, or process disclosed, or represents that its use would not infringe privately owned rights. Reference herein to any specific commercial product, process, or service by trade name, trademark, manufacturer, or otherwise does not necessarily constitute or imply its endorsement, recommendation, or favoring by the United States government or any agency thereof. The views and opinions of authors expressed herein do not necessarily state or reflect those of the United States government or any agency thereof.

Available electronically at http://www.osti.gov/bridge

Available for a processing fee to U.S. Department of Energy and its contractors, in paper, from:

U.S. Department of Energy

Office of Scientific and Technical Information

P.O. Box 62

Oak Ridge, TN 37831-0062

phone: 865.576 .8401

fax: 865.576 .5728

email: mailto:reports@adonis.osti.gov

Available for sale to the public, in paper, from:

U.S. Department of Commerce

National Technical Information Service

5285 Port Royal Road

Springfield, VA 22161

phone: 800.553 .6847

fax: 703.605.6900

email: orders@ntis.fedworld.gov

online ordering: http://www.ntis.gov/ordering.htm 


\section{Acknowledgements}

This work is made possible by the U.S. Department of Energy's (DOE) Hydrogen, Fuel Cells, and Infrastructure Technologies Program within the Energy Efficiency and Renewable Energy Office. The author would like to thank Margaret Mann, Ali Jalalzadeh, Mark Ruth, Todd Ramsden, and Darlene Steward of the National Renewable Energy Laboratory; Keith Parks of Xcel, Inc.; Tom Lambert of Mistaya Engineering; and Fred Joseck of DOE for their thoughtful insights through the development of this report. The author also thanks Karen Atkison for thoughtful editing of the report. 


\section{Abstract/Purpose}

This report provides a set of answers to the following questions regarding the future of hydrogen as a transportation fuel. The answers were determined by using the development of different scenarios run in the HyDS Modeling Environment (HyDS-ME), which is a geographically based supply and demand infrastructure model developed at the National Renewable Energy Laboratory between 2004 and 2006. The questions addressed are:

- Which technologies will be used to provide hydrogen during the deployment?

- What external influences and policies enable technologies to come online sooner?

- What synergies are there between cities and their distance to markets?

- How important and costly is it to serve rural areas?

- How can cities leverage one another's demand, thereby reducing cost and risk of stranded investments?

In order to answer the questions holistically and to attempt to gain further insights into the hydrogen infrastructure development, the all-encompassing question is: What are the impacts of different early infrastructure development scenarios? This report contains results of geographically rendered lower-cost, higher-impact early transition scenarios for developing hydrogen infrastructures using the HyDS-ME. Market and geographically targeted end-game scenarios for transition are designed based on historical transportation-sector transition trends, combined with current infrastructure scenarios developed for hydrogen by other researchers to identify scenarios likely to lead to nationwide infrastructure development.

Challenges to developing a hydrogen fuel infrastructure are large. Investment in both supply and demand infrastructure are required in concert with extensive technology and information delivery to the market. Scenarios developed from historical transitions in the sector contain aspects of the challenges for current and future infrastructure development. These aspects range from the relatively market-driven distributed generation of gasoline during its initial penetration to the nationwide, federally supported phasing out of methyl tertiary-butyl ether (MTBE) and technology changes such as the inclusion of catalytic converters in vehicles.

The HyDS-ME is used because of the model flexibility in setting both supply and demand assumptions (e.g., feedstock and technology price assumptions as well as assumptions for percentage of market penetration of light duty vehicles [LDVs]). Using both historical transitions as well as current research on likely market penetration and fuel prices, model scenarios identify possible geographic infrastructure development outcomes for hydrogen fueling. Outputs of the HyDS-ME scenarios include both a regional or national map, including pipeline and distributed infrastructure and a supply curve for the cost of fuel at various locations within the study area.

Model runs illustrate a wide breadth of results based on assumptions of market growth and development. First, findings indicate that targeted market development in high population density areas will lead to meeting near-term goals for infrastructure development. These targeted development scenarios leverage the demand of cities and nearby regions, reducing the risk of 
stranded costs for development and allowing the use of hydrogen to expand outside targeted. Second, varying end-use scenarios also showed that primary production technology varies from distributed generation to central generation with higher demand and more centralized development. Finally, some end-game technology and feedstock sensitivity scenarios show high variability in technology choice with relatively small changes to demand and price inputs.

The scenarios presented here provide a better understanding of likely technologies that will be used during deployment, show that targeted public policy for market development will lead to increased uptake of certain technologies, and indicate that the timing of the policies is critical to developing a lowest-cost fueling infrastructure. The report does not include estimates of annual pricing for different scenarios nor quantification of impacts beyond the development of the hydrogen infrastructure market (e.g., the impact of reduced central coal power plant development, regional challenges, and highly volatile land prices). Further research in these areas is possible with the tools used for these infrastructure developments, but those tools require more detailed inputs and use than this high-level assessment used to answer the initial questions presented above. 


\section{Table of Contents}

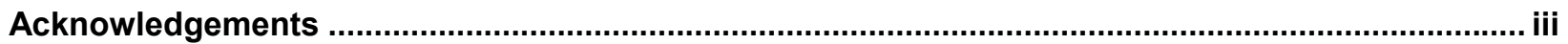

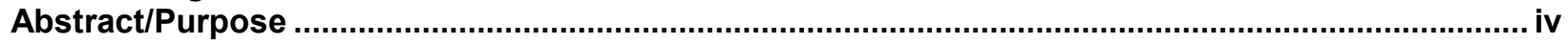

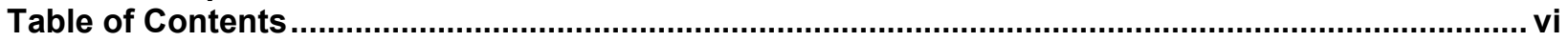

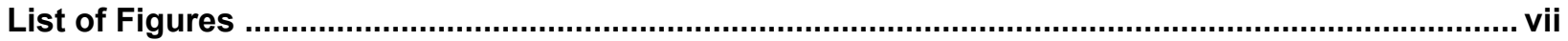

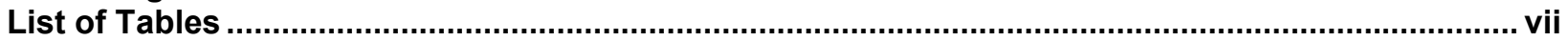

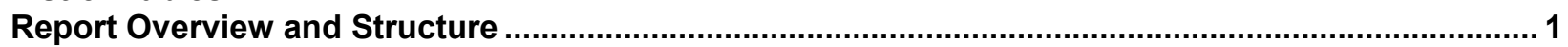

Transition in the Transportation Market ..................................................................................... 4

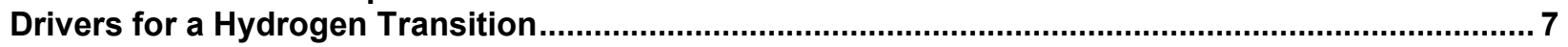

The Hydrogen Transition: What Does Supply Development Look Like? ...........................8

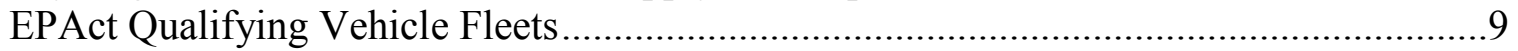

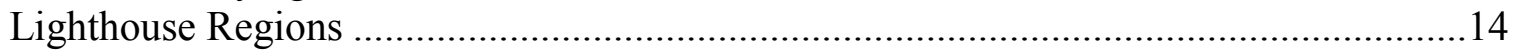

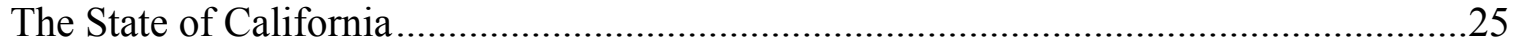

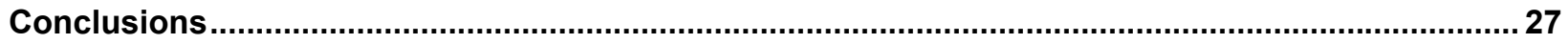

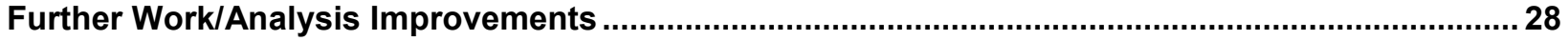

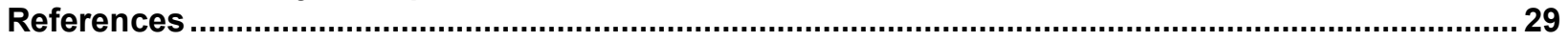




\section{List of Figures}

Figure 1. HyDS modeling environment visualization ...................................................... 8

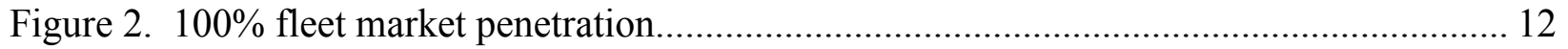

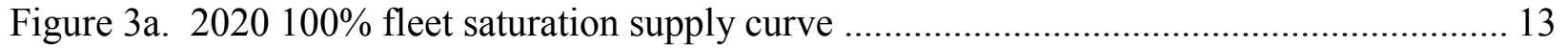

Figure 3b. 2036 100\% fleet saturation supply curve ......................................................... 13

Figure 4. Map and cost curve for the approximately 10 million residents ............................. 15

Figure 5. Map and supply cost curve for Midwestern region serving approximately 10 million

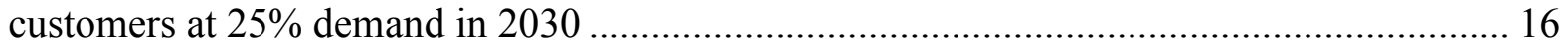

Figure 6. Map of Northeast lighthouse region (black box). Source: Google Earth ................. 17

Figure 7. Map of Southern California lighthouse region (black box) Source: Google Earth ...... 18

Figure 8. Map of Midwest lighthouse region (black box). Source: Google Earth.................... 19

Figure 9. Map of Northern California lighthouse region (black box). Source: Google Earth..... 20

Figure 10. 2026 Midwestern demand market penetration infrastructure output (black box

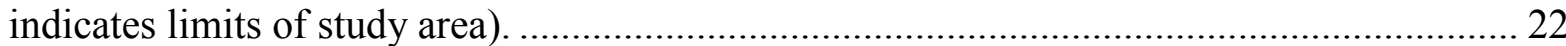

Figure 11a and b. 2026 Northern California demand market penetration infrastructure output (black box indicates limits of study area). .............................................................. 23

Figure 12. Modeled infrastructure development at varying demand levels in 2026 Northeastern

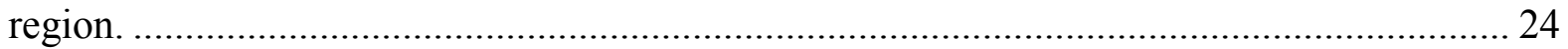

Figure 13. California hydrogen infrastructure development at different demand levels in 2025. 26

\section{List of Tables}

Table 1. Summary Assumptions for Fleet Scenarios........................................................ 10

Table 2. Summary of Fleet HyDS-ME Scenarios........................................................... 10

Table 3. Demographic and Scenario Summary for Building Lighthouse Region Infrastructure . 21

Table 4. California Hydrogen Infrastructure Scenarios (in 2025) .......................................... 25 


\section{Report Overview and Structure}

Creating a hydrogen transportation infrastructure includes simultaneous development of supply and demand. Transition of this type is typical in the transportation sector, and is accomplished through a drive toward innovation in the private sector and geographically targeted governmental support for early market development. For example, promoting the use of low-level ethanol blends through public-private innovation partnerships, has been shown to decrease air and water quality impacts.. Low-level blends are composed of up to 10 percent ethanol and 90 percent petroleum (E10). The high level of market penetration of these fuels results largely from public sector intervention requiring the use of ethanol. Today, the E10 market proceeds with minimal public policy interference, lessening human impact on the environment without appreciable cost to the consumer.

The low-level ethanol blend transition was relatively smooth because no infrastructure changes were necessary on either the supply or the demand sides of the market, and the environmental benefits outweighed the minimal cost of incorporating the additive. Market transitions are more complicated in a large, slow-turnover market (more than 200 million cars on the roads per U.S. Department of Transportation data for 2007) with broad geography and a large number of stakeholders (e.g., drivers, manufacturers, and the entire fuel supply chain) when those transitions include infrastructure change or behavioral paradigm shifts. For example, transitions that do require infrastructure or vehicle technology changes will not only involve multiple stakeholders, but also the sunk costs that must be overcome or fully realized before transition to new fuel types can occur. Changes that require modifying behavior, such as changing vehicle refueling locations and processes, can be interpreted as a burden on stakeholders and result in a more challenging transition. Introducing hydrogen fuel is an example of such a complicated transition.

This report describes a market transformation to hydrogen infrastructure that uses lessons learned from past transportation fueling transitions to efficiently and effectively grow a supply and demand for new infrastructure and technology for new fuel types. The first section (Transition in the Transportation Market) cites previous sector-wide changes that became increasingly complicated over time to illustrate the primary challenges associated with such a transition. These challenges include:

1. The entrenched fuel infrastructure is challenging to economically compete with because of its largely recovered capital cost (current gasoline market).

2. The necessity for major public and private impetus for change (MTBE and E10 as oxygenates).

3. The size of automobile fleet and the long turnover time for in-vehicle technology changes (catalytic converters and leaded fuel).

These challenges reflect the context in which the market for hydrogen is transformed. The examples show that efficient transition to a fueling system that requires changes to vehicles, infrastructure, and behavior will require extensive public and private support. Immediately following this background development, this report provides an overview of the HyDS-ME 
model, with reference to further information. The following section, The Hydrogen Transition: What Does Supply Development Look Like?, uses different assumptions about a possible hydrogen transition with the HyDS-ME to develop a number of possible low-cost outcomes of infrastructure development.

Several scenarios for initial development illustrate the large impacts of public policy choices for targeted development in two timeframes. The following scenarios are carried out assuming different policy timelines (2015 and 2026) and illustrate the impact of developing R\&D on potential stranded costs and technology choice in the near term:

- Government Fleets. This scenario targets federal and state fleets for development of an infrastructure. These fleets are geographically dispersed, allowing for a broad network of hydrogen infrastructure to develop over time.

- Lighthouse Cities. This scenario targets high density cities and regions to encourage widespread use of hydrogen fuel through high market penetration in concentrated areas. The nationwide network is expected to develop as demand expands beyond centralized hubs.

- The State of California. California represents a large percentage of the nation's vehicles and provides an environmentally motivated demographic. This scenario assumes the state will lead the effort in hydrogen market development.

Through this research and development of scenarios, the following general questions are addressed throughout the report:

- Which technologies will be used to provide hydrogen during the deployment? The technology chosen depends on the assumptions about the timeline for infrastructure development. Differences in timing of policy options and government-supported infrastructure roll-out lead to different outcomes of infrastructure development.

- What external influences and policies enable technologies to come online sooner? Feedstock price uncertainty and differences in the area of demand (see lighthouse study scenarios) lead to the different levels and types of technologies developing within the hydrogen infrastructure. Policies and other external technology development or changes in consumer demand strongly influence when different technologies will be chosen. For example, the California scenario illustrates the impacts of differing demand.

- What synergies are there between cities? A major finding of this report is that infrastructure scenarios in highly dense population centers are more likely to develop lowercost infrastructure (in cost per kilogram of fuel) than those in lower population centers for a greater number of consumers, measured by number of light duty vehicles (LDVs). Highpopulation cities in close proximity to one another (e.g., as in the northeast United States) boost this effect because of the very large population served in a smaller area. All scenarios illustrate the impact of hydrogen development in regions where cities are in close proximity. Through scenario development and model runs, the proximity of cities is a major driver in development of hydrogen infrastructure. The model illustrates that initial infrastructure focused on dense areas, as opposed to broad government-supported market development in 
less populated areas, will lead to lower cost of fueling overall. Cost reductions are the result of both economies of scale in production (e.g., centralized versus distributed steam methane reforming $[\mathrm{SMR}]$ ) and reduced costs for transporting fuel to city gates.

- How important and costly is it to serve rural areas? Following on the previous question regarding synergies between cities, this question relates directly into the less populationdense areas. The scenarios show that these areas are more expensive to serve because the distributed production technology is more expensive in terms of cost per kilogram of hydrogen fuel. In addition, the cost of trucking fuel to urban area gates is more expensive per customer than larger-scale pipeline delivery. However, pipeline delivery is only costeffective for large-scale delivery, and rural areas do not warrant the capital expenditure of the pipeline, even at high market penetration. Based on the findings in this report, rural areas are not considered to be first steps in the development of least-cost national infrastructure.

- How can cities leverage one another's demand, thereby reducing cost and risk of stranded investments? The scenarios developed in this report show that proximity- and population-density-related demand assists cities in reducing stranded costs. If development is based on regional areas, such as those in the lighthouse city scenarios, cities will benefit from both proximity and demand. The timing of the development of infrastructure, however, has a large impact on the most cost-effective infrastructure development. For example, in the reference case, development of infrastructure in 2015 is expected to be largely developed using natural gas as a feedstock. Assumed price changes for natural gas and biomass by 2035 (Energy Information Administration 2006) will lead to the development of a biomass-based infrastructure for infrastructure developed later in the century. More research on the impacts of different development timing possibilities is necessary in order to determine the full impacts and extent of stranded costs.

The report concludes with a discussion of the relative impacts of public policy choices on the development of the hydrogen transport fuel market, including geographic targeting and timing in relation to technology $\mathrm{R} \& \mathrm{D}$. 


\section{Transition in the Transportation Market}

In the early $20^{\text {th }}$ century, gasoline vehicles faced a challenge to what new fuels face today. The gasoline market developed initially by overcoming the need for small volumes of fuel required by largely geographically dispersed areas by using small-scale delivery mechanisms, such as canned gasoline and mobile refueling stations (Melaina 2004). These mechanisms met the needs of the budding automobile industry with low-cost distribution methods, and the industry grew so quickly that by the 1930s the station refueling system was largely in place (Williamson et al. 1963).

This development of infrastructure was rapid in terms of the transportation sector, with the station-based nationwide delivery system in place within 30 years of the fuels mainstream introduction. Over the next 60 years, an intricate pipeline delivery infrastructure was developed to serve the increasing fueling needs of the United States. That pipeline development is still ongoing today. A century later, the success of the gasoline market development impedes the development of new and innovative fuel infrastructure because of the gasoline infrastructure's apparent lower cost. However, this apparent difference in cost is increasingly offset by the increasing presence of environmental and political drivers.

The market growth for E10 is a simple example of gasoline market penetration increases resulting from public and private impetus and action in the case of environmental drivers. In addition to not requiring infrastructure changes or altering vehicle performance, ${ }^{1}$ low level ethanol blends offset major health fears associated with methyl tertiary-butyl ether (MTBE), the most widely used oxygenate previous to the emergence of E10. MTBE leaking into and contaminating drinking water systems triggered a major reaction from policy makers and was used to justify rapid, mandated removal of MTBE from the fuel supply. In addition to the benefits of avoiding MTBE, E10 has been shown to reduce vehicle emissions and therefore reduce the impact of petroleum-based fuels in transportation (Putsche 2006). All of these drivers worked in concert to facilitate the transition.

An example of a more complicated technology and infrastructure change occurred in the transition from leaded to unleaded gasoline in the United States, beginning in the 1970s. In the late 1960s it became clear that lead additives to gasoline were causing significant health issues (Schwela and Phoenix June 2001). In 1970, President Nixon signed the Clean Air Act, including a mandatory but stepped transition from leaded to unleaded gasoline (PL 91-604). This stepped process gave the manufacturers of vehicles time to optimize automobiles to function with unleaded gasoline and for infrastructure delivery to change over to unleaded fuels. Despite the apparent danger of leaded gasoline and the federal mandate, the transition was not completed and the substance officially banned from U.S. highway vehicles until 1996, 26 years after the order for the transition (Thomas 1995).

\footnotetext{
${ }^{1}$ Low-level ethanol blends do not change automotive performance unless water penetrates the gas tank. Although there is concern that performance of vehicles will be compromised in some climates in winter months, when condensation can occur in the gas tank, the typical turnover of gasoline in tanks is rapid enough to minimize this risk.
} 
The transition from leaded to unleaded gasoline illustrates the significant time that transition in the transportation sector can take, regardless of public mandates and private sector efforts resulting from both the perceived and real costs of infrastructure changes. It also illustrates the challenge of the sheer magnitude of the U.S. LDV population: 240 million vehicles in 2006 (Federal Highway Administration 2006). Greene and Shafer (May 2003) estimate it takes about 15 years to complete fleet turnover to incorporate cost-effective technologies. In practice, this means that if a new technology is installed in all vehicles beginning in model year 2008, the earliest year for full market saturation is approximately 2023.

This lengthy turnover time for the fleet creates a challenge for transportation sector transitions to new technology even in the event of full industry buy-in to the process. In the Clean Air Act of 1964, Congress mandated a 90 percent reduction (PL 91-604) in auto emissions, and invited industry to determine the best way to accomplish this goal. The industry responded with the catalytic converter, a device that reduces emissions of vehicles before they leave the vehicle. The introduction of the catalytic converter began in 1974, and moved quickly through the market because it could be installed as a retrofit on cars already on the road to immediately reduce pollutants. Despite the mandate and industry support for transition, the transition to 100-percent market penetration of catalytic converters is ongoing because of the long turnover in the vehicles market.

All of these referenced historic transitions in the transportation sector can serve as lessons learned that can influence and improve the public/private process for transition to new transportation technologies. These are:

1. Transition in the sector takes a large impetus for change. Change requiring high capital costs in an entrenched sector demands a commitment from the public and private sectors. Historically, human health impacts have driven changes in the sector, and more recently, environmental health has also become a factor. Valuing the risks to human and environmental health and communicating that valuation to the public (and the public sector) is critical to the transition to a hydrogen fueling system.

2. Transition in the sector requires public policy. Because the gasoline infrastructure building costs have been internalized, there is a distorted price for gasoline relative to new fuel types. In addition, the adverse environmental impacts of gasoline are not incorporated into the market prices (although a wide variety of policy options are under review at the local to federal levels for monetizing these costs). The role for public policy is to evaluate the real prices of continued petroleum use and balance the costs of new fueling infrastructure.

Public policy for the hydrogen transition, because of the high capital costs and current rapid technology evolution,, would require a wide range of public policy, ranging from research and development to investment risk mitigation.

3. Transition in the sector requires industry buy-in. Even in the case of the catalytic converter, where industry designed the system for meeting the federal goal, there was a 
significant lag in meeting the mandate for market transformation. Without industry support and partnerships, the public effort will not gain enough momentum to continue.

4. Transition in the sector takes time. The turnover rate of the U.S. fleet is currently estimated to be 15 years. The transition to the hydrogen economy will require careful planning to minimize the time to transition. This efficiency will increase with increasing pressure from the drivers for the transition.

Economically efficient transition in the sector requires the confluence of all of these factors. These transitions provide important context for the transition to a hydrogen-fueled economy in terms of the level of effort (public and private), as well as time required for such an effort to occur successfully. The following section outlines the specific drivers for a hydrogen transition and the challenges and opportunities for each. 


\section{Drivers for a Hydrogen Transition}

The drivers for transition to the hydrogen economy are two-fold: national security and environmental. A hydrogen-fueled transportation sector has the potential to meet the goals of both drivers but requires public/private sector planning and development guidance to do so. Public policy and private industry will also support the drivers for increased hydrogen fuel use by developing cost-effective hydrogen technology options and incorporating the external costs of gasoline into the price paid at the pump. For each of the drivers there are specific challenges that must be addressed to develop an efficient and environmentally sustainable market for hydrogen fuel.

1. National Security. Reducing dependence on foreign fuels increases our national security by allowing a more balanced interaction with global politics. Reducing use of foreign fuels extends beyond offsetting petroleum-based fuels to growing markets for local fuel production and promoting the importance of self-sufficiency. In the case of hydrogen, using local resources to produce hydrogen vehicle fuels is required in the long term to meet the goal of increased national security. In the transition period, natural gas is assumed to be the primary feedstock for hydrogen because of its assumed availability and low price (relative to other feedstocks). Historically, natural gas has been less volatile in terms of national security than other fossil fuels, but the transition model used in our scenarios, HyDS-ME, considers the use of alternative hydrogen production technologies to meet the goals of this driver in the long term.

2. Reduced environmental impact of the transportation sector. Catalyzing behavioral changes, especially those with high costs based on environmental dangers, can be challenging when the impact is not direct and rapid (e.g., as with MTBE). However, the push to migrate to cleaner burning and locally created fuels is clear. The 2005 Yale Environmental Survey found that 92 percent of Americans feel that dependence on imported oil is a serious problem (Yale School of Forestry and Environmental Studies 2005). Another pressure to reduce petroleum-based transportation fuels is an increasing focus on air quality impacts both locally (e.g., particulate-related health impacts) and globally (e.g., contributions to climate change). In terms of hydrogen-fueled vehicles, multiple studies have shown that increased use leads to reduced emissions of both local and global pollutants (Colella et al. 2005). Hydrogen fuels produced with less impact than fossil fuel development will lead to less contribution to climate change. As in reaching the goal of national security, facilitating the transition to a hydrogen economy economically will require a transition in steps from technologies that reduce climate change impacts slowly to those that offset impacts quickly. In reality, aside from abstaining from transportation, hydrogen is the only long-term fueling option that has the potential to reduce fossil fuel emissions from the U.S. transportation sector to near zero, but the initial transition will focus more on reduction rather than eradication for economic reasons.

The strongest factor for transition to hydrogen fuel in the transportation sector is the magnitude of drivers for change, including reduced dependence on foreign fuels and decreased environmental damage, which encompasses reducing U.S. impacts on global climate change. 
Transition, however, is a challenge under the best of conditions, and can be an economically inefficient process. The scenarios presented in this report suggest that lowest-cost development (including stranded costs) may result from market infrastructure developing in a timely fashion with decreasing technology prices resulting from $R \& D$. These implications require further development and study to refine our understanding of the balance between market and technology development. The following section uses these lessons learned from previous transitions to suggest targeted market development strategies that have the potential to build the market for hydrogen supply. The supply can be built to meet the level of demand estimated by multiple sources to create a self-sustaining and growing hydrogen market nationwide.

\section{The Hydrogen Transition: What Does Supply Development Look Like?}

In this section, lessons learned from transportation transitions are used to develop and illustrate multiple scenarios for hydrogen supply market development. The HyDS-Modeling Environment is used to illustrate possible build-outs of supply infrastructure. Several background documents that are publicly available summarize the structure, data inputs, and assumptions of the modeling environment (Parks 2006, Lambert 2006). The model is unique in visualizing hydrogen infrastructure development because it offers a regional perspective with data granularity down to the urban area level, considers spatial relationships between markets, and competes production and delivery technologies to estimate the least-cost scenario (Parks 2006). Figure 1 offers a summary visual representation of the environment.

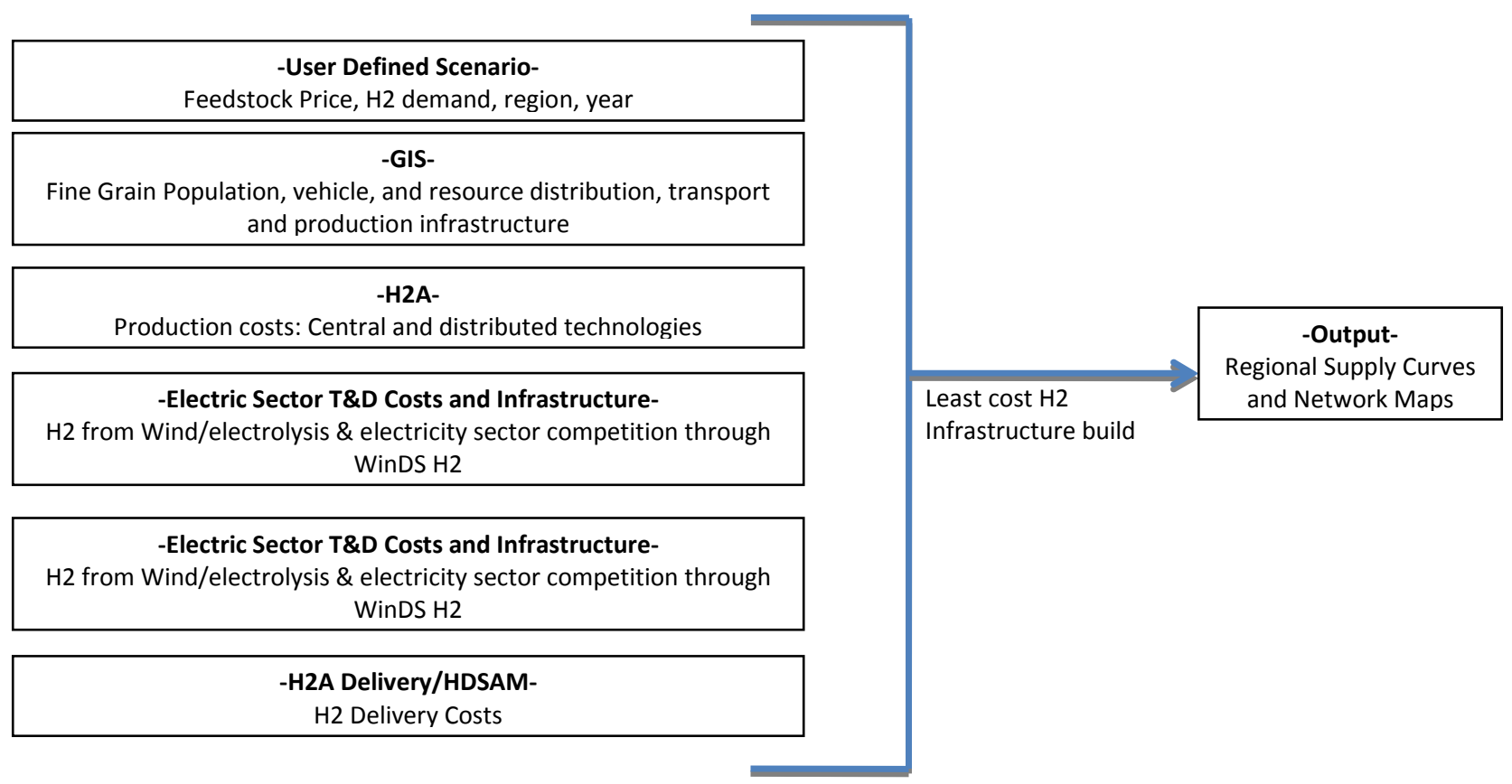

Figure 1. HyDS modeling environment visualization 
The user inputs all of the scenario parameters such as demand level, region, and year that the demand will be met. Other inputs to the model include geographic population, resource, and transportation infrastructure from geographic imaging systems. Production and delivery costs are input from $\mathrm{H} 2 \mathrm{~A}$ and $\mathrm{H} 2 \mathrm{~A}$ Delivery. The HyDS-ME includes dynamic system modeling aspects for electric sector and transmission and delivery (T\&D) costs for 358 distinct regions through WinDS H2, but that is not used in the following preliminary scenarios. The HyDS-ME was chosen for this application based on the capability of the model to specify regionality to a fine level and illustrate regional and local distribution and growth potential differences.

Scenarios chosen for modeling were aiming to maximize infrastructure in place and advance existing market-building policy mechanisms based on lessons learned from the past. Targeting specific markets or sets of stakeholders allows for maximum impact. In the transportation sector, there are a number of focus markets targeted in market transformation:

\section{EPAct Qualifying Vehicle Fleets}

Private, state, and federal fleets are targets for incorporating new technologies into the transportation sector, but yield somewhat limited results. This strategy relies on the centralized regulation of fleets to maximize impact of expenditures. However, evidence does not clearly reflect the success of this strategy in triggering market transformation, likely because of the complexities associated with designing effective legislation for centralized fleets and the relatively small number of vehicles in fleets, relative to privately owned vehicles. (Fleets account for only 10 percent of vehicles and 5 percent of fuel use nationwide.) As an example of fleet targeting, EPAct (1990) required qualifying public fleets to include an increasing number of alternative fuel vehicles (AFVs) since 1990. While this regulation increased AFVs in qualifying fleets, it has significantly increased alternative fuel use (most new vehicles are flex fuel vehicles and use gasoline). Nor has the regulation led to adoption of AFVs by the broader consumer market.

General assumptions for the fleet scenarios are laid out in Table 1. Today's fleet vehicles make up about 10 percent of the total vehicle market, but use only 5 percent of the total vehicle fuel because fleet vehicles, on average, drive half the annual miles of privately owned vehicles. The scenarios assume this ratio to be constant into the future. In addition, fleet distribution is assumed to mirror the geographic distribution of vehicles, ${ }^{2}$ and is also expected to remain constant over time.

Assumed demand for fleet vehicles is divided into six scenarios summarized in Table 2. The scenarios offer two timelines: one is longer, completing the transition in 2035, and another includes more aggressive policies, saturating in the nearer term, 2020. A range of fleet market penetration is assumed: 33 percent, 66 percent, or 100 percent to illustrate the impacts of low to high penetration of that market. Because fleets are 10 percent of the total national vehicle fleet, the total market penetration estimates are 3.3 percent, 6.6 percent, and 10 percent.

\footnotetext{
${ }^{2}$ Data on geographic fleet distribution is a challenge to acquire. A large portion of the federal fleet is operated by agencies headquartered in Washington, DC, so many of those vehicles are reported as "garaged" in DC, when they are physically in another location. This assumption, that the fleet is proportional to the total LDV population, reflects the likely light duty fleet vehicle distribution.
} 
Table 1. Summary Assumptions for Fleet Scenarios

1. Fleet population and distribution proportional to national fleet population

2. Relative fleet fuel use remains constant over time.

Table 2. Summary of Fleet HyDS-ME Scenarios

\begin{tabular}{|c|c|c|c|}
\hline Scenario Number & Penetration of Fleets & Total US LDV penetration & Year Build-Out Complete \\
\hline $1 \mathrm{a}$ & $33 \%$ & $3.3 \%$ & \multirow{3}{*}{2020} \\
\hline $2 \mathrm{a}$ & $66 \%$ & $6.6 \%$ & \\
\hline $3 a$ & $100 \%$ & $10 \%$ & \\
\hline $1 b$ & $33 \%$ & $3.3 \%$ & \multirow{3}{*}{2036} \\
\hline $2 b$ & $66 \%$ & $6.6 \%$ & \\
\hline $3 b$ & $100 \%$ & $10 \%$ & \\
\hline
\end{tabular}

Based on these assumptions, meeting fleet demand scenarios will not lead to a national pipeline network of hydrogen fueling in either of the 2020 or 2036 timeframes. Assuming that the introduction of mandatory hydrogen fuel use in all fleet vehicles by 2020 leads to a similar demand in consumer vehicles, a major pipeline system will not result from the demand. These results indicate that a national hydrogen fueling infrastructure is unlikely to result from a fleet focus on initial development because of the lack of density in vehicles to justify widespread pipeline delivery.

Specifically, the results show that pipelines are built only in very densely populated areas (Figure 2) and the following limited, densely populated urban areas chose central generation:

- Northern California

- Southern California

- Washington/Baltimore corridor

- Miami

- Chicago

- Phoenix-Mesa

- Dallas/Fort Worth/Arlington

- Denver/Aurora 
- Detroit

- Minneapolis-St. Paul

- New York/New Jersey/Philadelphia corridor.

All other areas chose distributed generation to meet demand. Distributed production at lower population densities is expected as it minimizes transportation costs. 


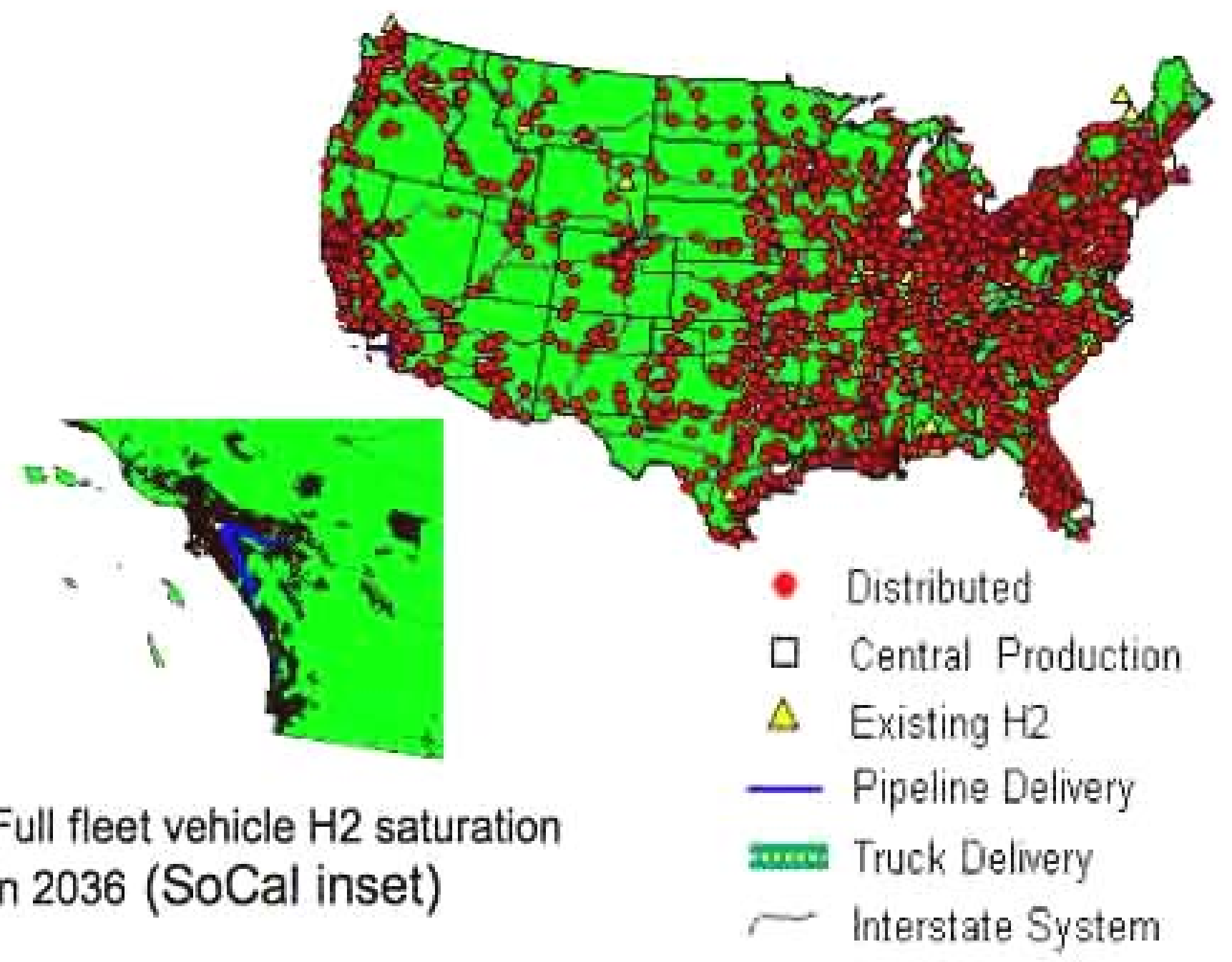

Figure 2. $100 \%$ fleet market penetration 
One major difference between meeting the fleet market penetration goals in the near term and waiting until the longer term was the choice of feedstock for central generation. Technology improvement and increasing natural gas competition lead to a shift to biomass feedstock as the modeled lowest-cost production method in the longer term. Figure $\mathbf{3} \boldsymbol{a}$ shows central SMR lowest-cost option up to about 3.5 million cumulative $\mathrm{kg} /$ day, indicating that density to that level of demand supports the costs of pipeline infrastructure. Beyond that, distributed SMR is the most cost effective. If the construction of a hydrogen infrastructure is delayed until 2036, technology cost reductions and assumed natural gas price increases lead to central biomass as a feedstock up to $3,5000,000 \mathrm{~kg} / \mathrm{day}$, transitioning again to distributed SMR

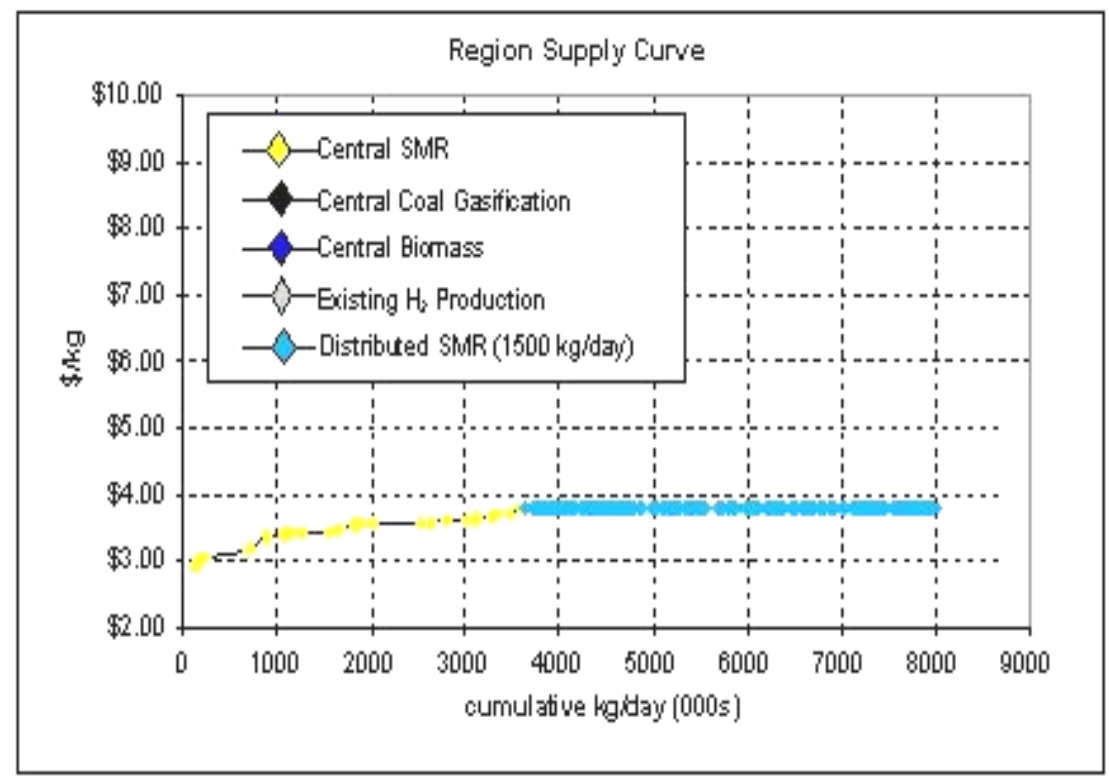

Figure 3a. $2020100 \%$ fleet saturation supply curve

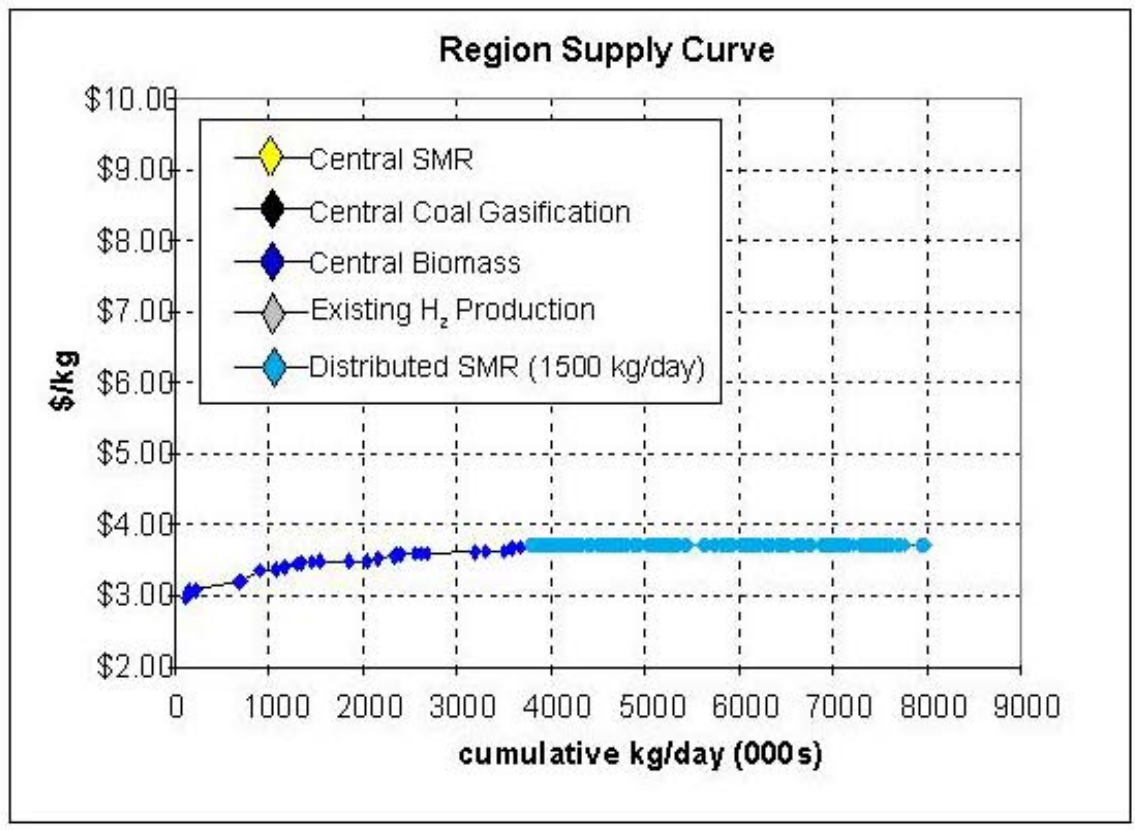

Figure 3b. 2036 100\% fleet saturation supply curve 
The scenarios show that the infrastructure choice for non-urban areas is distributed production of hydrogen fuel from natural gas. While this would support the needs of the fleets, it is not scalable infrastructure that can be delivered to the general public through the network of the distributed station model of the current fueling paradigm for two primary reasons. First, because it is least cost, fleets may choose to build their hydrogen fueling at centralized fueling locations, as is the model for some alternative fuels. These stations are inconvenient or inaccessible to many private drivers and do not support the development of scalable infrastructure. Second, if the increase in distributed stations for fleets did lead to market acceptance and increased penetration in the consumer sector, research indicates that the physical size of distributed fueling stations is prohibitive to large-scale installation (Melendez and Milbrandt October 2006).

\section{Lighthouse Regions}

Another strategy for building early infrastructure is to target high-impact condensed geographic areas for initial technology build-out to decrease infrastructure prices with increasing economies of scale and to maximize the hydrogen benefit for every dollar invested in infrastructure. This strategy is supported in and outside the United States as a viable strategy for build out (BMW Group et al. ND, Greene et al. 2008). Evidence from research indicates that there can be as much as a doubling of projected hydrogen fuel prices between metropolitan and nonmetropolitan areas (Singh et al. 2005). This price disparity indicates that lowest-cost infrastructure development will occur in large, densely populated cities. Scenario runs using HyDS-ME illustrate the change in hydrogen fuel cost in different regions with different population densities and illustrate higher costs for rural areas. To show this, the population of Los Angeles County, approximately 10 million, and several Midwestern states with the same population, only much less dense, were compared for possible infrastructure developments meeting 25 percent of demand in 2030 using HyDS-ME.

Figure 4 illustrates the map and regional cost curve for Los Angeles, the densely populated area. The cost of the single distributed generation system is about $\$ 3.00$ per kilogram of hydrogen.

Figure 5 is a representation of the same population size over a much larger area. The majority of the demand in that larger region needs to be met by more distributed systems, at a cost around $\$ 4.00$ per kilogram of hydrogen. Finally, transition in the transportation sector has successfully taken this approach historically, as with the gasoline infrastructure presented in the report overview. 

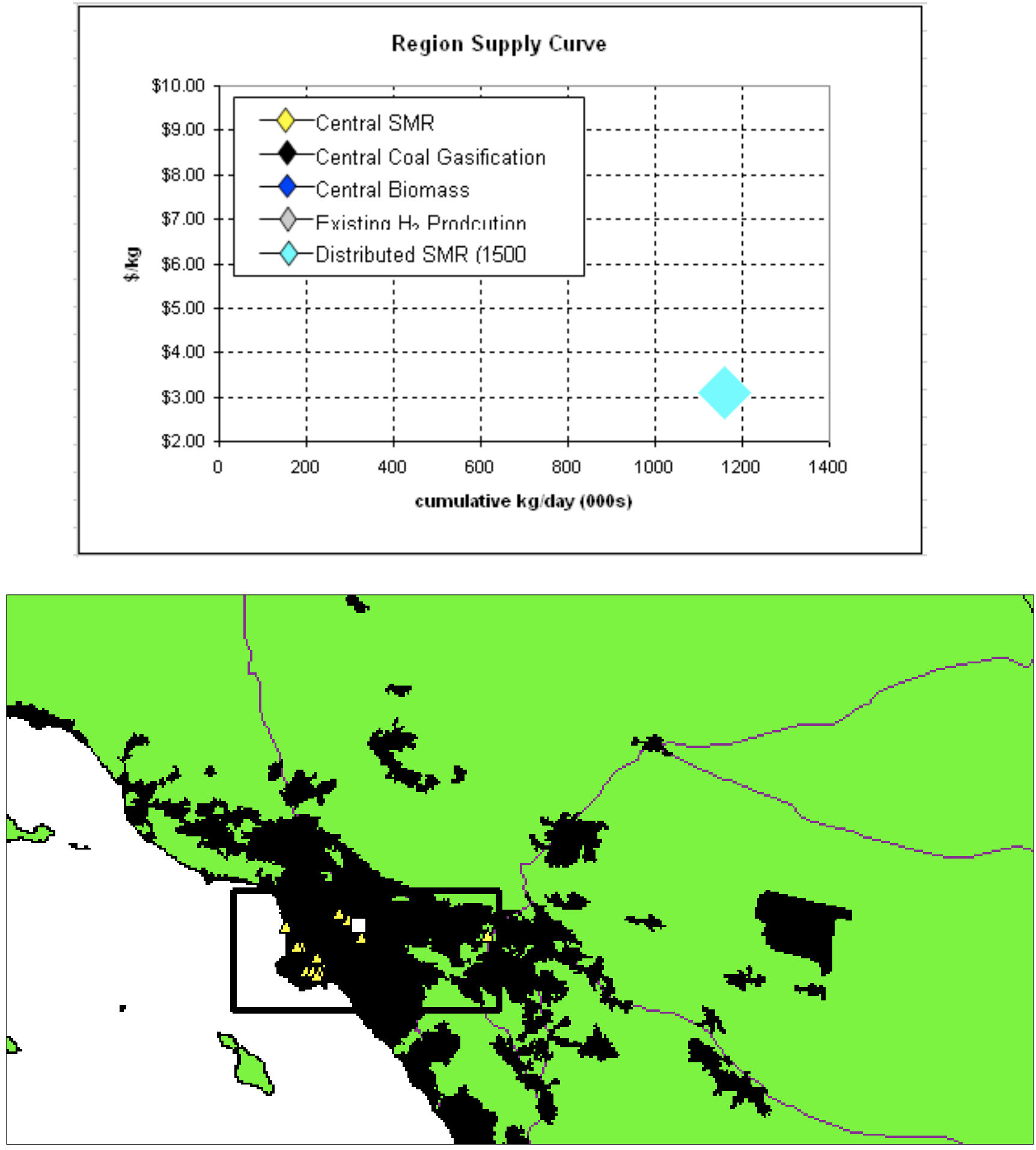

Figure 4. Map and cost curve for the approximately 10 million residents 

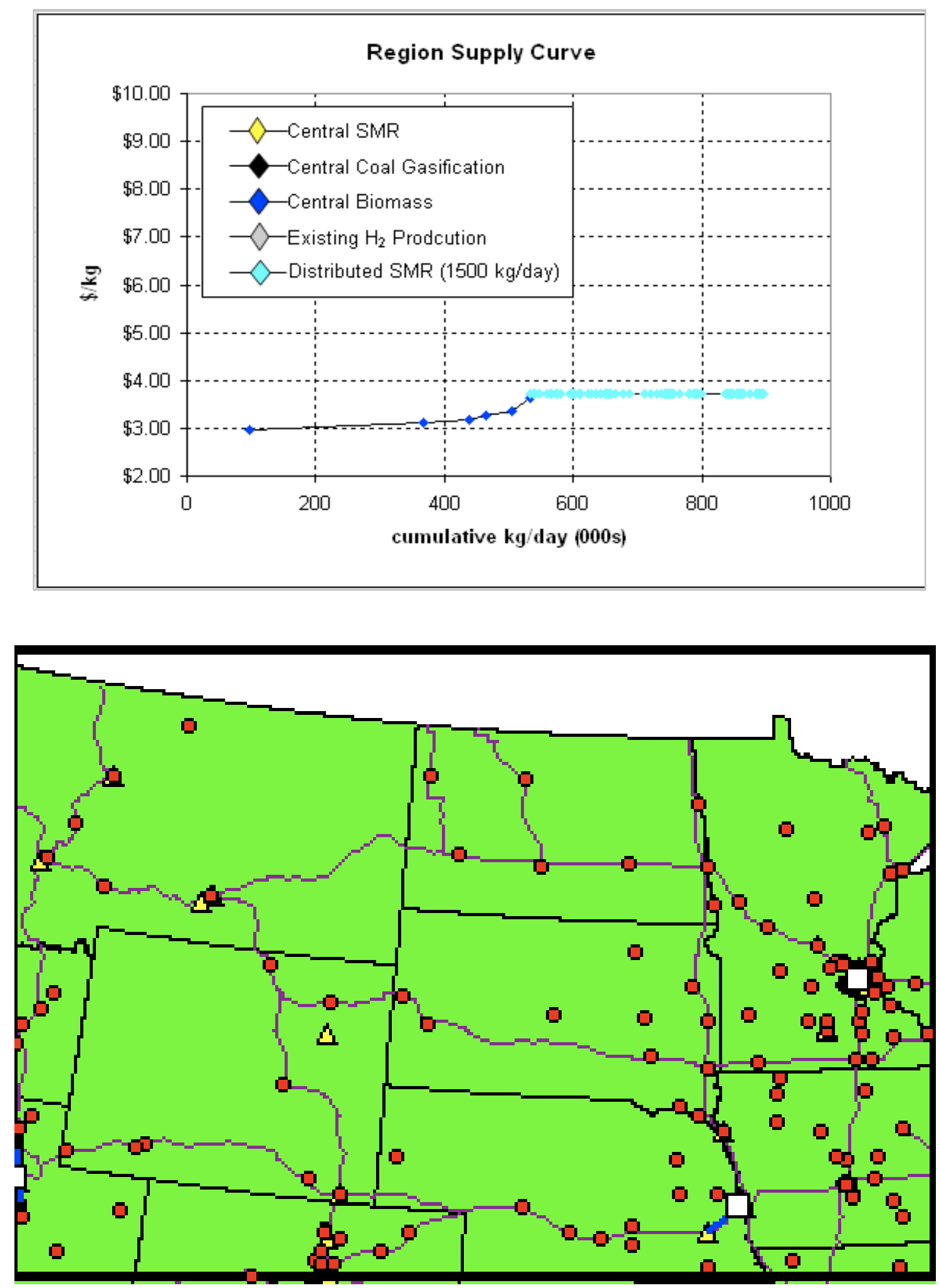

Figure 5. Map and supply cost curve for Midwestern region serving approximately 10 million customers at $\mathbf{2 5 \%}$ demand in $\mathbf{2 0 3 0}$ 
To graphically represent possible infrastructures in densely populated areas, areas of high population density as represented by Condensed Metropolitan Statistical Areas (CMSA) are selected. These top CMSAs make up 20 percent of the U.S. passenger vehicle population. Because of the population density of the New England-Mid-Atlantic region (and modeling limitations, discussed below), those areas are merged into a single study area (New Hampshire-Virginia), resulting in four study lighthouse areas. Maps of these areas follow.

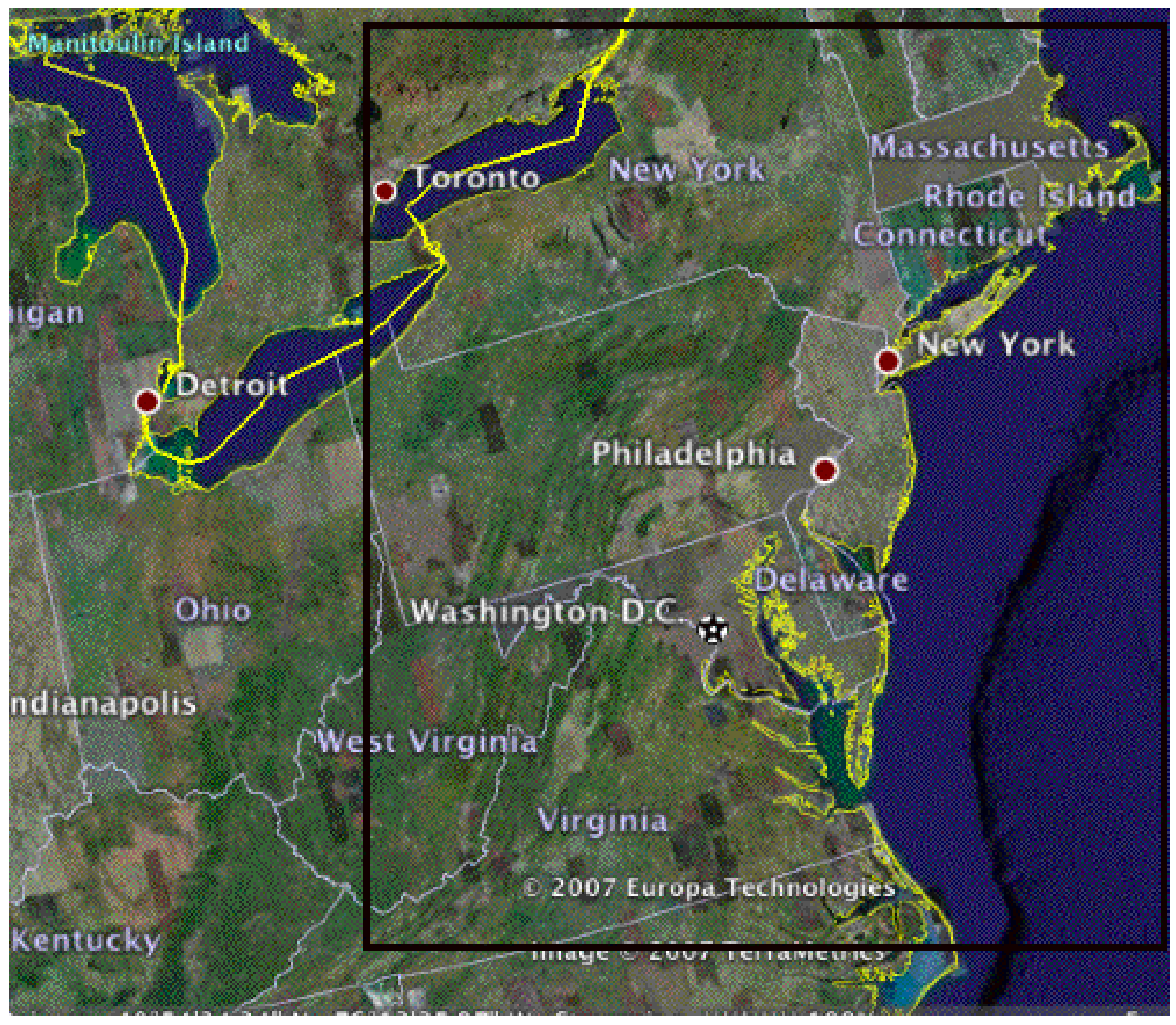

\section{New Hampshire to Virginia}

This study area includes areas as far northeast as Rochester, New Hampshire, west to Lake Ontario and as far south as the southern border of Virginia, including all of Pennsylvania. Combining these CMSAs required the inclusion of some less dense areas, further increasing the number of vehicles in these areas.

Figure 6. Map of Northeast lighthouse region (black box). Source: Google Earth 
Southern California - This lighthouse region is made up of the Los Angeles-Riverside-Orange County, CA CMSA

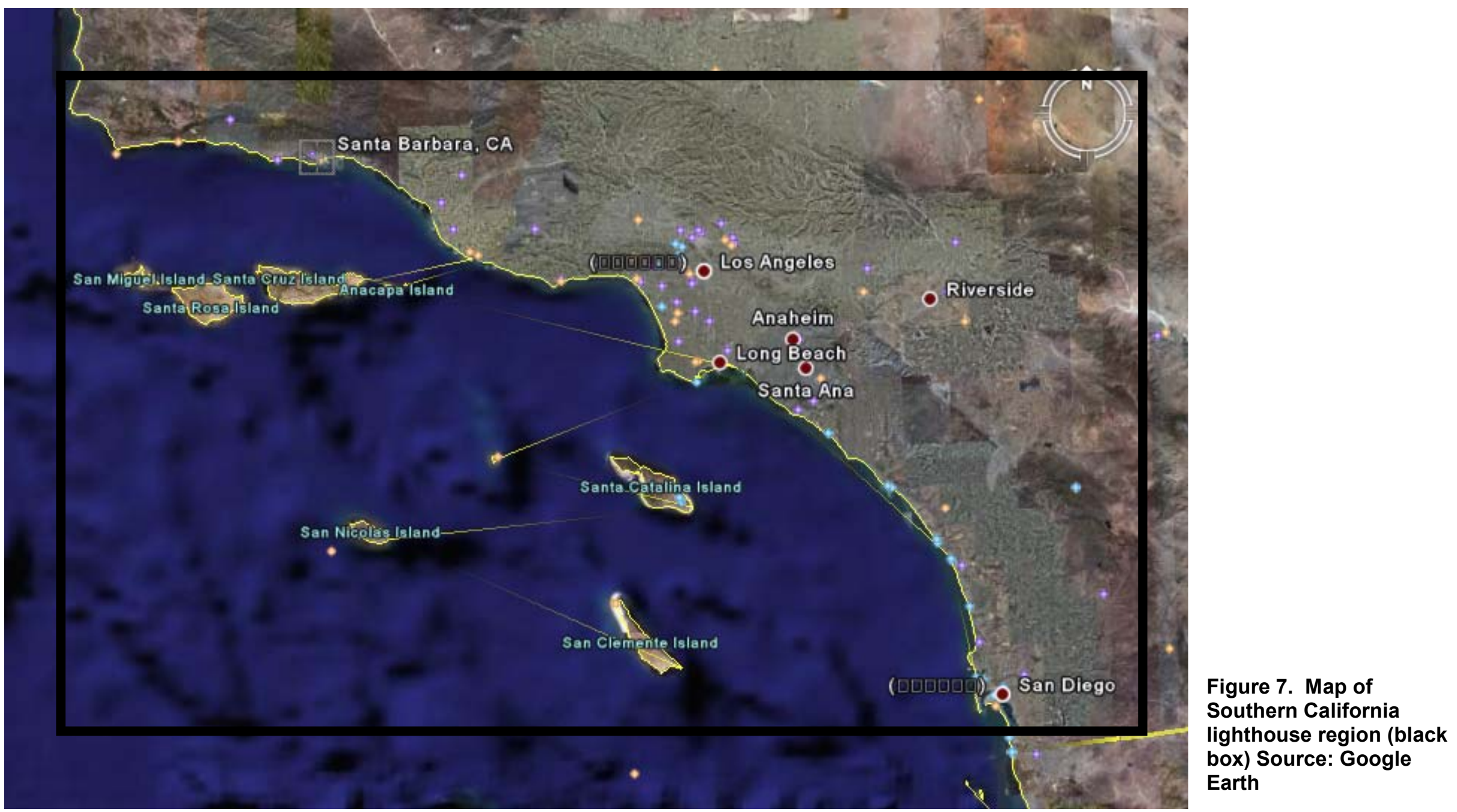


Midwest - The Midwestern region is defined as the Chicago-Gary-Kenosha IL-IN-WI CMSA.

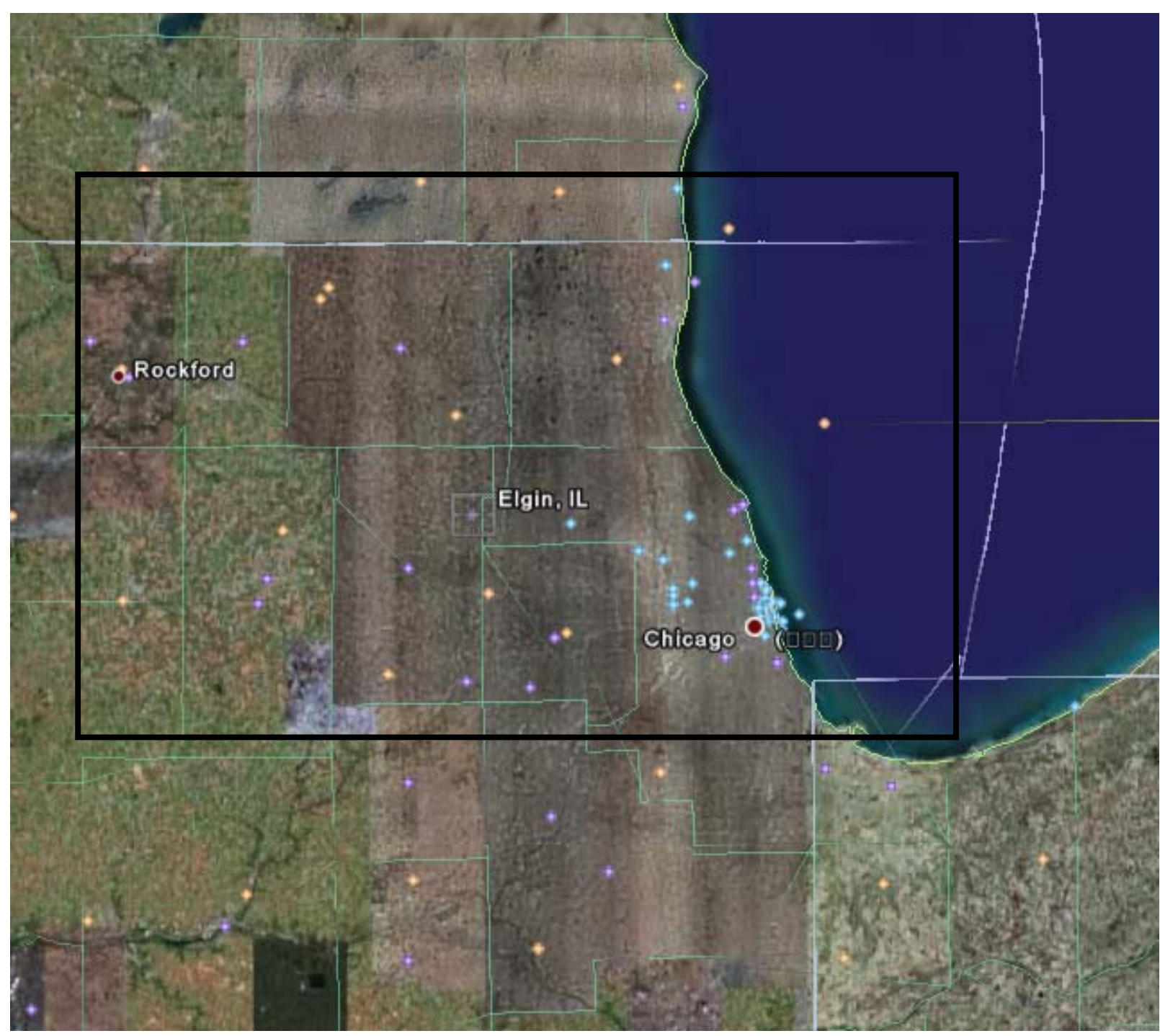

Figure 8. Map of Midwest lighthouse region (black box). Source: Google Earth 
Northern California . This lighthouse region is made up of the San Francisco-Oakland-San Jose, CA CMSA.

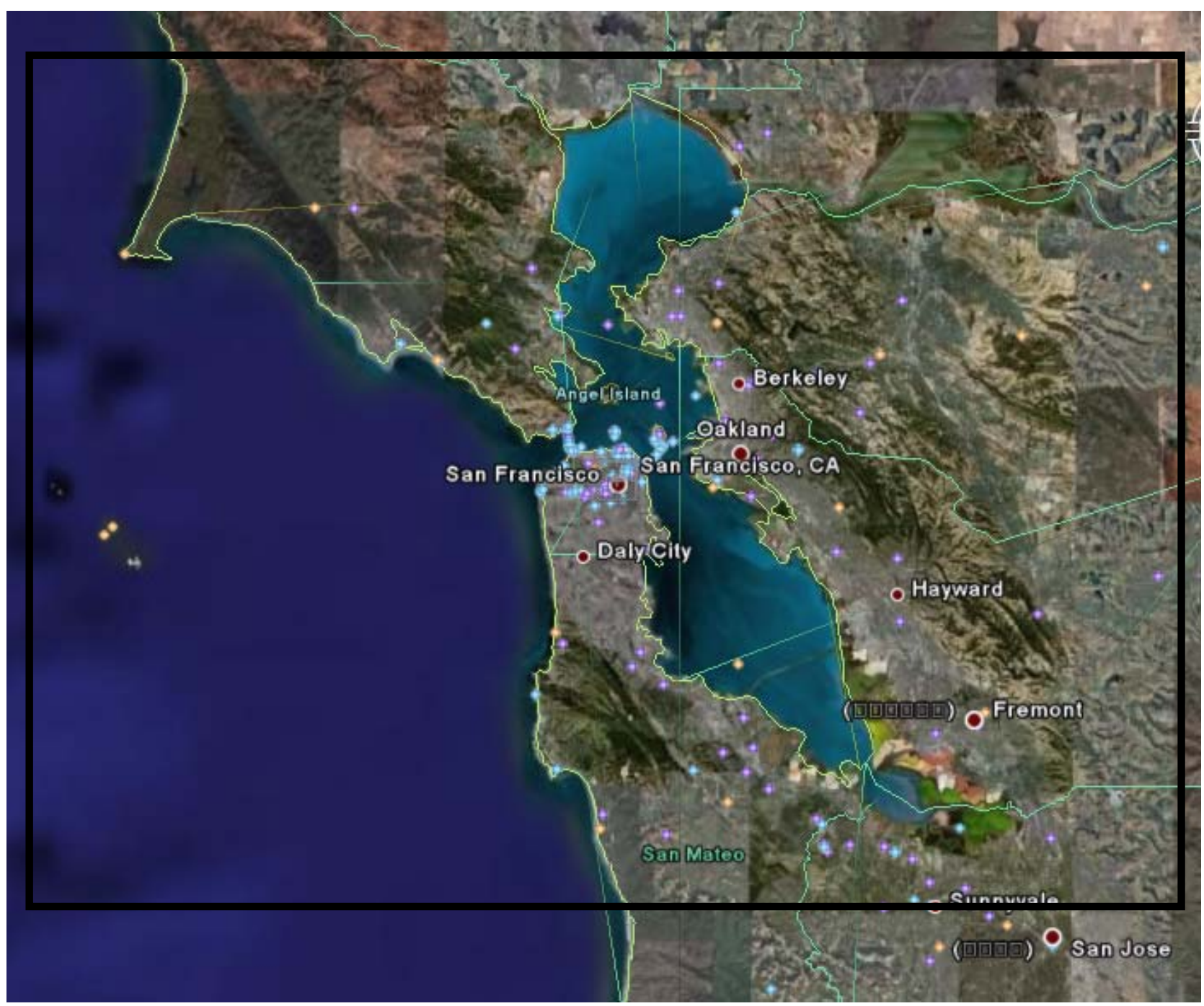

Figure 9. Map of Northern California lighthouse region (black box). Source: Google Earth 
Table 3 details the relevant demographics of these study areas, as well as the demand scenario assumptions used in modeling potential infrastructure building. National-level vehicle population data reported by the vehicle population projections are based on current vehicle counts in the area (Census 2000). Note that the table values are estimates based on geographic area data available.

Table 3. Demographic and Scenario Summary for Building Lighthouse Region Infrastructure

\begin{tabular}{|c|c|c|c|c|c|c|}
\hline \multirow{2}{*}{ Study Area } & \multicolumn{2}{|c|}{$\begin{array}{l}\text { Passenger Vehicle } \\
\text { Population }\end{array}$} & \multicolumn{4}{|c|}{$\begin{array}{l}\text { Number of Vehicles } \mathrm{H} 2 \text { in } 2026 \text { by } \\
\text { Scenario }\end{array}$} \\
\hline & $2000 *$ & $\begin{array}{l}\text { Projected } \\
2025 * *\end{array}$ & $5 \%$ & $15 \%$ & $30 \%$ & $50 \%$ \\
\hline $\begin{array}{l}\text { 1) } \\
\text { New } \\
\text { Hampshire to } \\
\text { Virginia }\end{array}$ & $21,400,000$ & $32,900,000$ & $1,645,000$ & $4,935,000$ & $9,870,000$ & $16,450,000$ \\
\hline $\begin{array}{l}\text { 2) Southern } \\
\text { California }\end{array}$ & $10,500,000$ & $16,000,000$ & 800,000 & $2,400,000$ & $4,800,000$ & $8,000,000$ \\
\hline 3) Midwest & $7,000,000$ & $10,300,000$ & 515,000 & $1,545,000$ & $3,090,000$ & $5,150,000$ \\
\hline $\begin{array}{l}\text { 4) Northern } \\
\text { California }\end{array}$ & $5,200,000$ & $7,700,000$ & 385,000 & $1,155,000$ & $2,310,000$ & $3,850,000$ \\
\hline Total Vehicles & $44,100,000$ & $66,900,000$ & $3,345,000$ & $10,035,000$ & $20,070,000$ & $33,450,000$ \\
\hline $\begin{array}{l}\text { \% Total US } \\
\text { Passenger vehicle } \\
\text { stock }\end{array}$ & $21 \%$ & $21 \%$ & $1.0 \%$ & $3.1 \%$ & $6.1 \%$ & $10.2 \%$ \\
\hline
\end{tabular}

* Assumes Bureau of Transportation Statistics (BTS) total passenger vehicle population (2000) and urban area Census 2000 proportions for household vehicles in associated specific regions. Methodology adapted from Keith Parks' work (unpublished).

** Assumes average annual growth rate of 1.7\% (5-year growth rate from BTS MV-1 Dataset) 
In these lighthouse scenarios, all lighthouse regions except the Midwest use pipe building as the least-cost option beyond 15-percent vehicle penetration (Figure 10). The Midwestern scenario uses pipes as infrastructure beyond 30-percent penetration, but at 15-percent penetration uses larger central generation plants and trucking of fuels. This is likely a result of highly compact demand in this scenario, leading to lower fuel transportation costs across the region.

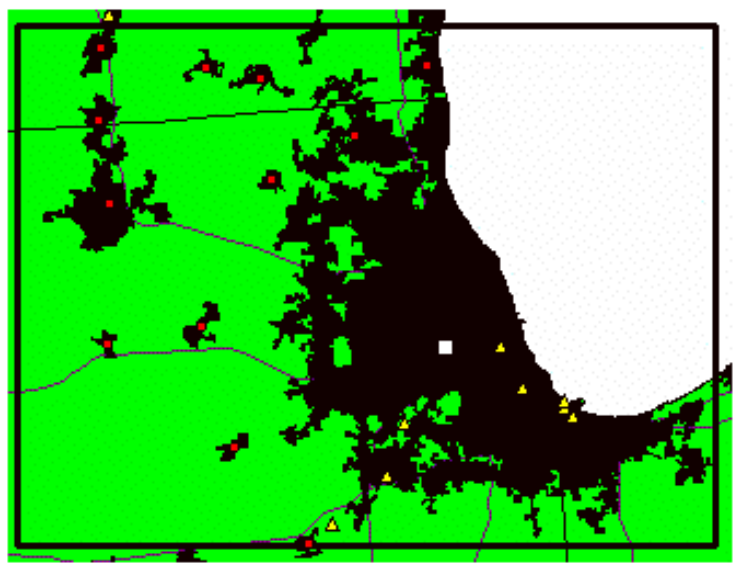

a: $15 \%$ Penetration

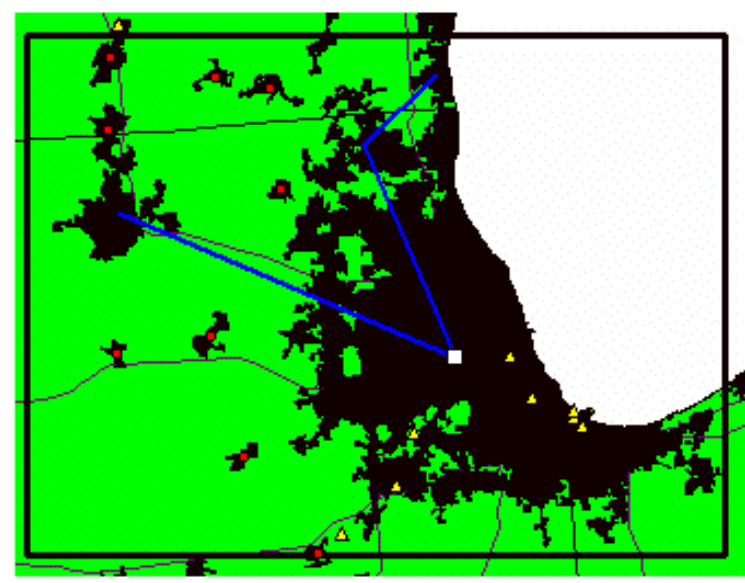

b: $30 \%$ Penetration

Figure 10. 2026 Midwestern demand market penetration infrastructure output (black box indicates limits of study area). 
In the remaining, larger geographic scenarios, the pipelines are built at 15-percent market penetration. As assumed demand in scenarios increases, the pipeline build-out can change physically. In the Northern California 30-percent scenario, for example, there is a pipeline built from downtown San Francisco to the southern tip of San Francisco Bay (Figure 11a). When expanded to a 50-percent penetration scenario, a central station plant is built in the high-density area at the south end of the bay, negating the need for a pipeline (Figure 11b).

This situation reflects the importance of effectively targeting infrastructure growth in policy making. While more research is required to define the policy goals that maximize scalability and minimize risk, this finding indicates that rapid development of new and evolving technologies in hydrogen development could lead to significant stranded costs.

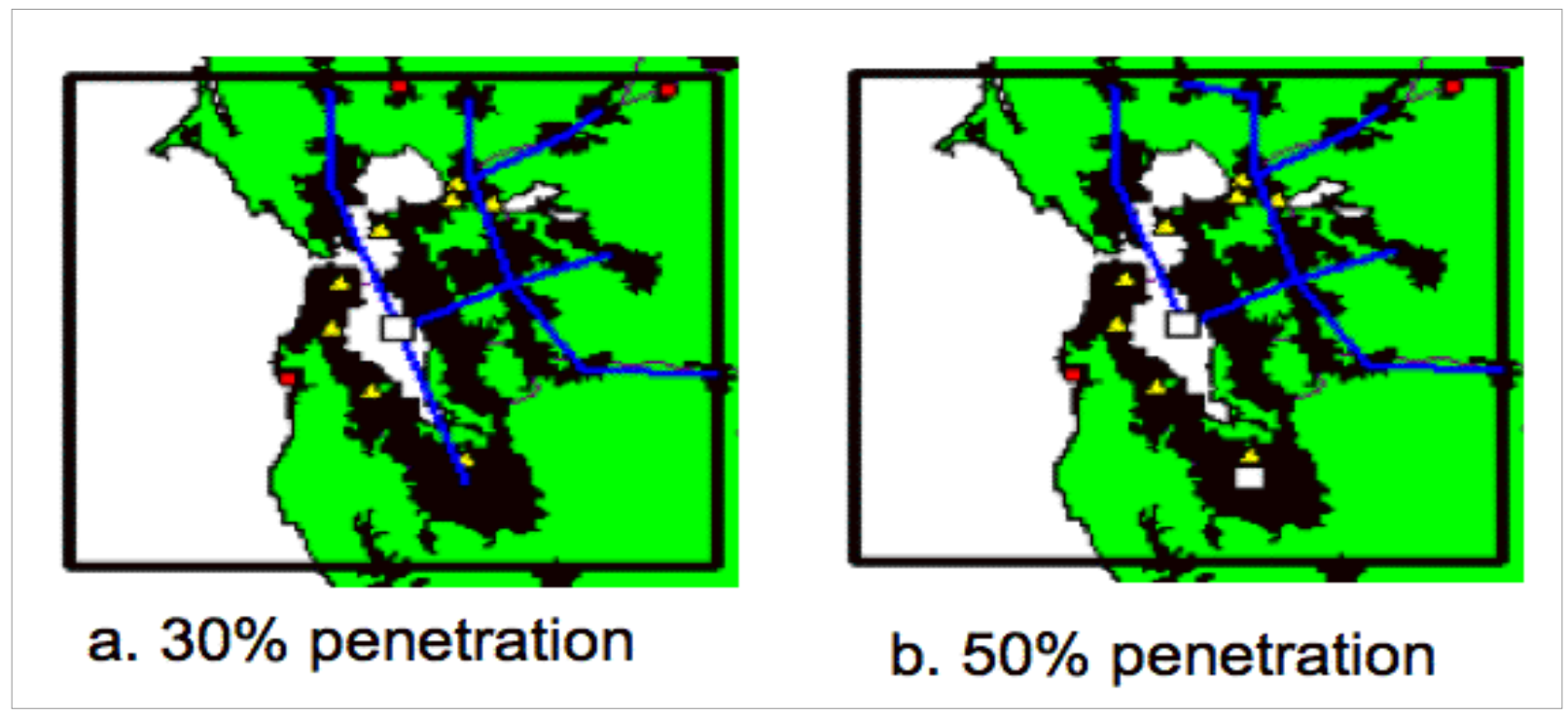

Figure 11a and b. 2026 Northern California demand market penetration infrastructure output (black box indicates limits of study area).

The Northeastern scenario presents an example of the highest consistent population over a relatively small geographic area in the United States. Targeting infrastructure in this area may minimize the high-cost growth issues presented in the Northern California scenarios. Costs can be reduced because of the near-immediate need for large-scale hydrogen production and distribution at relatively small demand levels. 
Figure 12 shows the four scenarios for 2025 development based on varying demand. At 15percent demand, five central station production facilities are lowest-cost providers: Boston; New York,; Philadelphia; Washington, DC; and Pittsburgh. In all cities but Pittsburgh (the city in which demand drops off the fastest, geographically) pipelines connect nearby non-central generation metropolises (e.g., Baltimore is connected by pipeline to Washington, DC). At a 30percent demand level, the pipelines reach to lesser-populated areas and a new central production plant off Lake Erie serves large sections of highly populated upstate New York. Interestingly, at this point, the production facility in New York City is not connected by pipeline, as the high demand in that location minimizes the need for transportation of fuels, making truck transport the least-cost option.

Less actual demand in New England allows for the Boston plant to be the least-cost pipeline fuel provider through most of central and southern Connecticut. Increasing demand for fuel to 50 percent of vehicles in the region triggers the building of three additional central production facilities (nine in total), including southern Virginia. Even at this high level of relative demand, however, distributed production plays a relatively large role in serving the demand, and the scalability implications of that are uncertain.
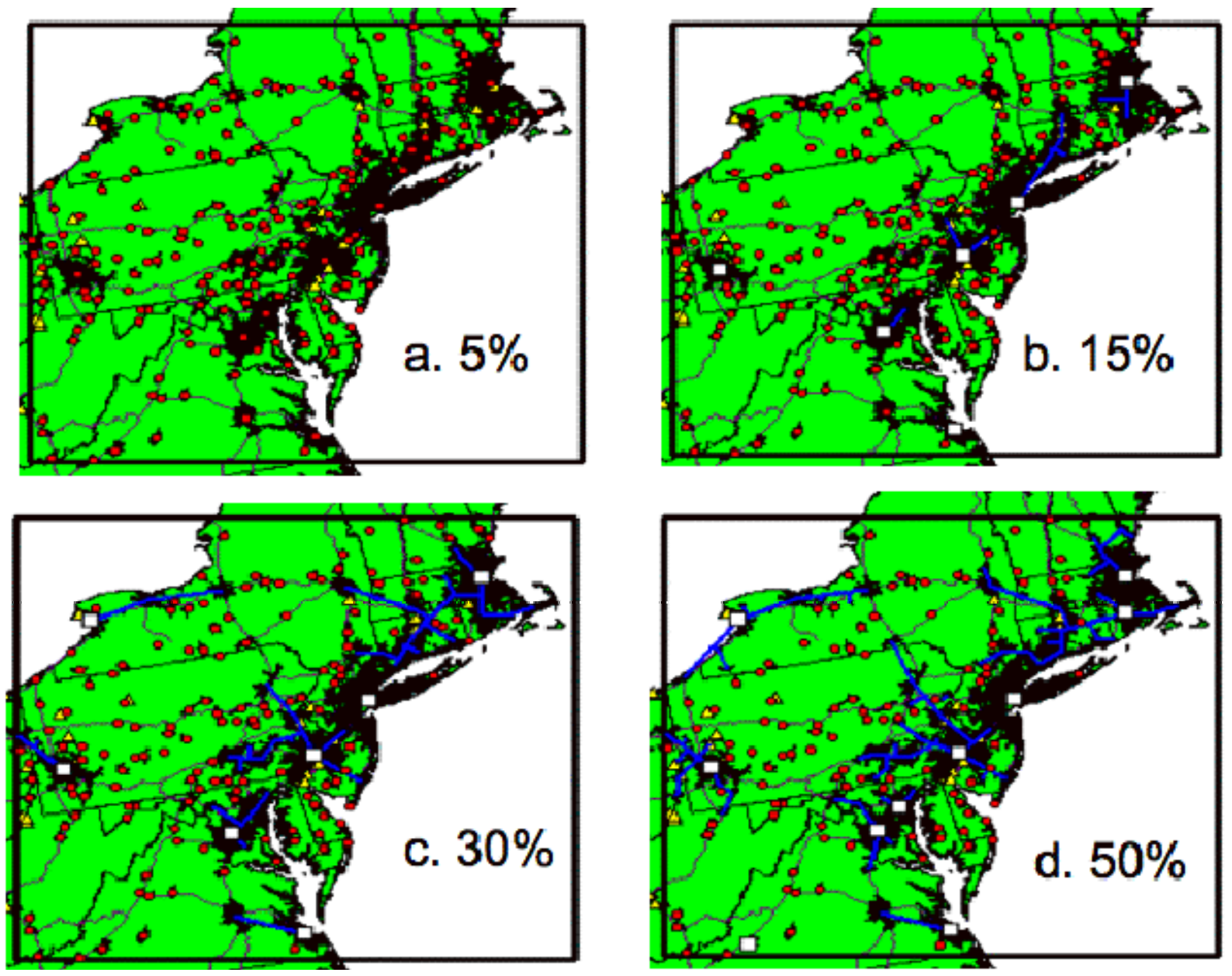

Figure 12. Modeled infrastructure development at varying demand levels in 2026 Northeastern region. 


\section{The State of California}

Another possible scenario to develop initial infrastructure for hydrogen is to limit the geographic area to a high-population, environmentally motivated area with a history as a market forerunner willing to take large financial risks: California. Limiting the study to market penetration in California has benefits beyond the state being a general trendsetter for advanced technologies (e.g., stem cell research, the low-carb revolution, and merlot). Such benefits include:

1. Geography: The state of California limits the national geographic area, thereby reducing fuel transportation costs as the demand market builds.

2. Population: While the size is restricted, 12 percent of automobiles registered in the United States in 2000 were registered in California (Bureau of Transportation 2001).

3. Demographic: Californians are environmentally motivated and have historically exhibited high willingness to pay for improving the environment.

To illustrate the potential geographic build-out of infrastructure in California the HyDS-ME is used to test the state as a single lighthouse region for 11 demand scenarios. The market development window is the same as the national and city/region lighthouse window for appropriate comparison, assuming a completed penetration by 2025 . The scenarios include a 5percent market penetration and then penetrations at every 10-percent interval starting at 10 percent. Each of the scenarios with the approximate number of hydrogen automobiles is presented in Table 4.

Table 4. California Hydrogen Infrastructure Scenarios (in 2025)

\begin{tabular}{|c|c|c|}
\hline \begin{tabular}{c} 
Penetration Scenario \\
\hline $5 \%$
\end{tabular} & $\begin{array}{c}\text { Number of H2 Vehicles } \\
\text { (millions) }\end{array}$ & $\begin{array}{c}\text { Percent of Projected } \\
\text { US Passenger Fleet }\end{array}$ \\
\hline $10 \%$ & 1 & $<1 \%$ \\
\hline $20 \%$ & 2 & $1 \%$ \\
\hline $30 \%$ & 4 & $3 \%$ \\
\hline $40 \%$ & 6 & $4 \%$ \\
\hline $50 \%$ & 8 & $5 \%$ \\
\hline $60 \%$ & 10 & $6 \%$ \\
\hline $70 \%$ & 11 & $8 \%$ \\
\hline $\mathbf{8 0 \%}$ & 13 & $9 \%$ \\
\hline $90 \%$ & $\mathbf{1 5}$ & $\mathbf{1 0 \%}$ \\
\hline $100 \%$ & 17 & $12 \%$ \\
\hline & 19 & $13 \%$ \\
\hline
\end{tabular}


Similar to the lighthouse scenario model, the California scenarios show a low penetration outcome, preferring distributed generation and a scaled preference for central generation and pipes as demand increases (Figure 13).

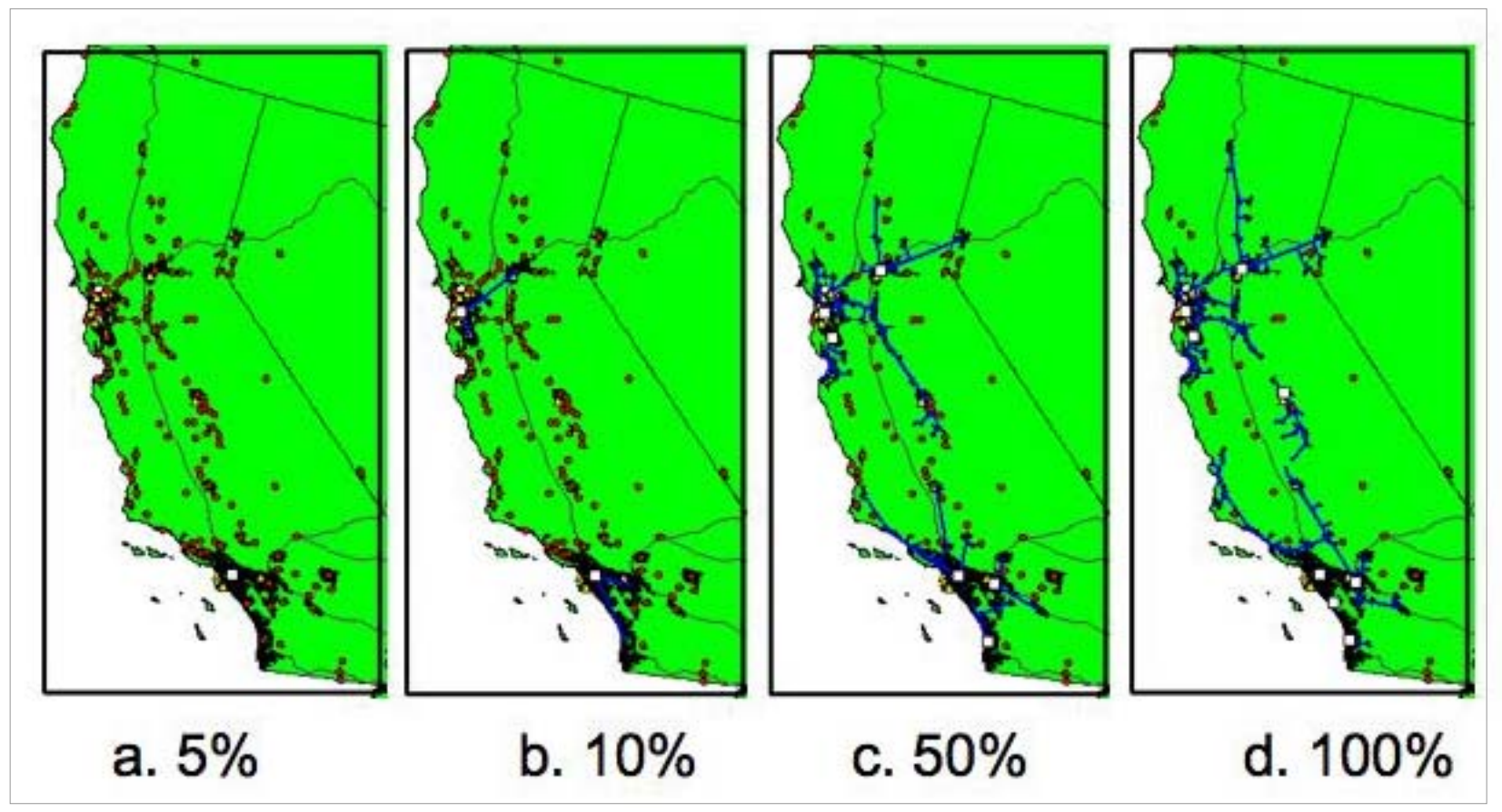

Figure 13. California hydrogen infrastructure development at different demand levels in 2025.

The pattern of the piping changes with the level of demand, in accordance with the initial demand patterns for vehicle use and cost effectiveness of transporting fuel. At 90-percent vehicle demand, the maximum number of least-cost central generation plants are built, primarily along the coastline, with the final three serving the inland areas. Between 90-percent and 100-percent market penetration and minimal pipeline building occurs and the number of distributed plants drops by only two in favor of pipelines. ${ }^{3}$

In the lowest-demand scenario (5 percent), only the Los Angeles area has enough demand to have a central plant that would be lowest cost. In the 10-percent scenario, the region is expected to begin building pipeline infrastructure. This is consistent with the expected behavior in this region for both fleet vehicle and lighthouse region scenarios presented above. Another result that implies the importance of developing policy goals for demand, is that the lower penetrations, to 50 percent, trend toward a statewide pipeline system to meet increased demand. At demands of 60 percent, however, there are clear areas (coinciding with overall vehicle demand density) where distributed production of hydrogen will be least cost.

\footnotetext{
${ }^{3}$ Interestingly, HyDS-ME builds one scenario with a central generation coal gasification plant beginning at 90 percent of the vehicle market demanding hydrogen fuel. Based on recent legislation in California, this is an exceptionally unlikely scenario and requires further scrutiny.
} 


\section{Conclusions}

Based on historical transitions in the transportation sector and the drivers for hydrogen transition, targeted market development scenarios are suggested as options for hydrogen infrastructure development. In this paper, three primary scenarios for targeted development are created and tested using the HyDS-ME to visualize the scenarios: EPAct qualifying fleets, lighthouse cities, and the state of California. Each of these targeted markets has potential benefits and drawbacks for extensive market development over time. Each targeted market also possesses the important factors that inform public policy making for hydrogen market development.

In the fleet models scenario, the distribution of hydrogen infrastructure does not develop far beyond distributed production of hydrogen, even in the most populated areas because of the low overall demand of fleets. While fleets may be centrally regulated and offer a targeted market, market development focus does not result in widespread, scalable supply development. Targeted geographic markets, or lighthouse cities/regions illustrate a more geographically centralized market, and modeling indeed shows development of scalable infrastructure in higher density regions. However, this geographically targeted development may not expand to more rural areas quickly. Finally, the state of California, a state with a history of advanced technology development and high national security and environmental priorities, offers a mix of highly dense vehicle distribution and rural areas. Although limiting the development to the state of California could result in 13 percent of the national market and a mix of rural and urban market development, development across the nation is unlikely to be quick or least-cost driven if infrastructure is initially limited to the west coast.

Other interesting results stemmed from the case studies, including the incremental price increases caused by including initial rural development. The fleet development scenario showed the challenges of developing the hydrogen market when demand density is low, such as it is in rural areas. In all scenarios, the most rural of the areas established distributed fuel production facilities and fuel was trucked to delivery locations. This low density does not allow for rapid increased market development in the near term, because the development of small distributed generation production plants are complicated to scale up, and low population limits increases in demand that would lead to large plants and scalable pipeline infrastructure.

Modeling for California shows that the largest regional infrastructure is a mix of pipelines and truck delivery, depending on total demand density. This model confirms the necessity of appropriate governmental support for the market, because the goal of infrastructure support is to find the balance between developing scalable infrastructure and minimizing the risk to investment in building central facilities and pipelines. These results show, through different infrastructures built at different demand densities, that determining the correct size of production facility for long-term growth is critical.

These geographic modeling efforts illustrate the importance of considering geographic demand density patterns and demonstrate potential strategies to create drivers for hydrogen infrastructure through targeted infrastructure development. 


\section{Further Work/Analysis Improvements}

Given that geographic demand and infrastructure are critical to the efficient development of hydrogen infrastructure, further work with the HyDS modeling environment could include the following efforts.

- Further integration of the growth scenarios -A component of HyDS-ME can develop an infrastructure in steps through time. This piece of the modeling environment is currently available for select cities in the United States and requires demand and data inputs, including improved demand-growth scenarios and rates. When such models showing enhanced capability are completed, they could illustrate geographically the impacts of increasing demand over time, including the sunk costs of failing to account for scalability in policymaking.

- Determining the impact of waiting to build and implement infrastructure.- With adjustments, HyDS-ME can illustrate more detailed impacts of delaying infrastructure construction and implementation.

- Analyzing economic impacts - Use economic development tools, such as JEDI, to estimate the local economic impacts of installation and increased demand of hydrogen.

- Further investigate implications of high-density areas as triggers for a national infrastructure. This report finds that increasing the focus on highly dense areas is likely to stimulate creation of a national-level infrastructure for hydrogen fuel delivery. This finding has implications that will need to be further investigated. For instance, land prices and availability of land in urban areas for reformers or distribution centers could be of larger concern in these areas. 


\section{References}

Bureau of Transportation Statistics (2001). State Vehicle Statistics, http://www.bts.gov/publications/state_transportation_statistics/california/html/table_05_01.html. Accessed March 2007.

BMW Group, DaimlerChrysler AG, Ford Motor Company, General Motors Europe AG, MAN Nutzfahrzeuge AG, Shell Hydrogen B.V. Total France, and Volkswagen AG (ND). "Next Steps for the Development of a Hydrogen Infrastructure for Road Transport in Europe." A common position paper of BMW Group, DaimlerChrysler AG, Ford Motor Company, General Motors Europe AG, MAN Nutzfahrzeuge AG, Shell Hydrogen B.V. Total France and Volkswagen AG.

Colella, W.; Jacobson, M.; Golden, D. (2005). "Switching to a U.S. Hydrogen Fuel Cell Vehicle Fleet: The Resultant Change in Emissions, Energy Use, and Greenhouse Gases." Journal of Power Sources, (Vol. 150) pp. 150-181.

Energy Information Agency (2006). U.S. Department of Energy, Annual Energy Outlook 2006. Reference Case - Table 11

Federal Highway Administration (2006) U.S. Department of Transportation. "Facts, Statistics, and Data." http://safety.fhwa.dot.gov/facts/. Accessed July 2008.

Greene, D., Leiby, P.; James, B.; Perez, J.; Melendez, M.; Milbrandt, A.; Unnasch, S.; Hooks, M. (2008). "Analysis of the Transition to Hydrogen Fuel Cell Vehicles and the Potential Hydrogen Energy Infrastructure Requirements." ORNL/TM-2008/30. Oak Ridge, TN. Oak Ridge National Laboratory.

Greene, D.; Shafer, A. (May 2003) "Reducing Greenhouse Gas Emissions from U.S. Transportation." Prepared for the Pew Center on Global Climate Change. San Francisco, CA Pew Center, 80 pp.

Lambert, T. "Overview of HyNOON." http://mistaya.ca/hynoon/HyNOONOverview20061220.pdf. Accessed July 2008.

Melaina, M. (2004) "Turn of the Century Refueling: Lessons from the Past for Introducing Hydrogen Fuel for 21st Century Vehicles." Proceeding of the National Hydrogen Association 2004 Annual Conference.

Melendez, M.; Milbrandt, A. (October 2006). "Geographically Based Hydrogen Consumer Demand and Infrastructure Analysis: Final Report." NREL/TP-560-40373. Golden, CO: National Renewable Energy Laboratory, 35 pp.;

Parks, K. (2006) "Hydrogen Deployment System Modeling Environment (HyDS ME) Documentation: Milestone Report FY 2006". NREL/MP-560-40763. Golden, CO: National Renewable Energy Laboratory, 29 pp.;

Putsche, V. 2006. Personal communication of research results and DOE Technical Assistance Project. 
Schwela, D.; Phoenix. J. (June 2001) "Leaded Gasoline: An overview of environmental and health impacts." Presented at the Conference on Phasing-out leaded Gasoline Dakar, Senegal. June 2001, pp. 26-28

Singh, M.; Moore, J.; Shadis, W. (2005) "Hydrogen Demand, Production, and Cost by Region to 2050." Prepared for DOE/EERE. ANL/ESD/05-2. Oak Ridge, TN: Argonne National

Laboratory.

Thomas, V. (1995) "The elimination of lead in gasoline." Annu. Rev. Energy Environ. (20: 301324).

Williamson, H.; Andreano, R.; Daum, A; Klose, G. (1963) The American Petroleum Industry: The Age of Energy 1899-1959. Evanston, IL: Northwestern University Press, 1963.

Yale School of Forestry and Environmental Studies. (2005) "Survey on American Attitudes and the Environment - Key Findings: New Haven, CT: Yale Press. 


\section{REPORT DOCUMENTATION PAGE}

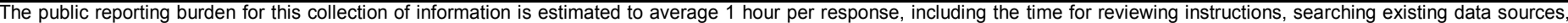

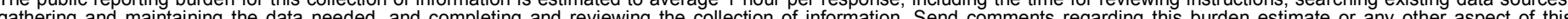

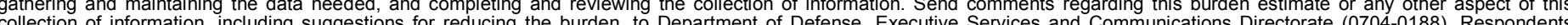

should be aware that notwithstanding any other provision of law, no person shall be subject to any pena

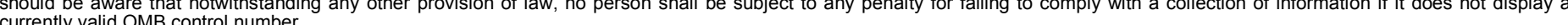

PLEASE DO NOT RETURN YOUR FORM TO THE ABOVE ORGANIZATION.
1. REPORT DATE $(D D-M M-Y Y Y Y)$
27-08-2008

\section{REPORT TYPE}
TP
3. DATES COVERED (From - To) June 2007 to December 2007

4. TITLE AND SUBTITLE

Transportation Sector Market Transition: Using History and

Geography to Envision Possible Hydrogen Infrastructure

Development and Inform Public Policy 5a. CONTRACT NUMBER

DE-AC36-99-G010337

5b. GRANT NUMBER

5c. PROGRAM ELEMENT NUMBER

5d. PROJECT NUMBER

NREL/TP-670-43497

5e. TASK NUMBER

$\mathrm{H} 278.2700$

5f. WORK UNIT NUMBER
7. PERFORMING ORGANIZATION NAME(S) AND ADDRESS(ES)

National Renewable Energy Laboratory

1617 Cole Blvd.

Golden, CO 80401-3393
8. PERFORMING ORGANIZATION REPORT NUMBER

NREL/TP-670-43497

9. SPONSORING/MONITORING AGENCY NAME(S) AND ADDRESS(ES)

10. SPONSOR/MONITOR'S ACRONYM(S) NREL

11. SPONSORING/MONITORING AGENCY REPORT NUMBER

12. DISTRIBUTION AVAILABILITY STATEMENT

National Technical Information Service

U.S. Department of Commerce

5285 Port Royal Road

Springfield, VA 22161

13. SUPPLEMENTARY NOTES

14. ABSTRACT (Maximum 200 Words)

This report covers the challenges to building an infrastructure for hydrogen, for use as transportation fuel.

Deployment technologies and policies that could quicken deployment are addressed.

15. SUBJECT TERMS

hydrogen infrastructure; hydrogen policies; hydrogen deployment; hydrogen fuel; transportation

\begin{tabular}{|c|c|c|}
\hline 16. SECURIT & CLASSIFICATI & OF: \\
\hline $\begin{array}{l}\text { a. REPORT } \\
\text { Unclassified }\end{array}$ & $\begin{array}{l}\text { b. ABSTRACT } \\
\text { Unclassified }\end{array}$ & $\begin{array}{l}\text { c. THIS PAGE } \\
\text { Unclassified }\end{array}$ \\
\hline
\end{tabular}

\begin{tabular}{|c|c|}
\hline $\begin{array}{l}\text { 17. LIMITATION } \\
\text { OF ABSTRACT }\end{array}$ & $\begin{array}{l}\text { 18. NUMBER } \\
\text { OF PAGES }\end{array}$ \\
\hline UL & \\
\hline
\end{tabular}

19a. NAME OF RESPONSIBLE PERSON

19b. TELEPHONE NUMBER (Include area code) 